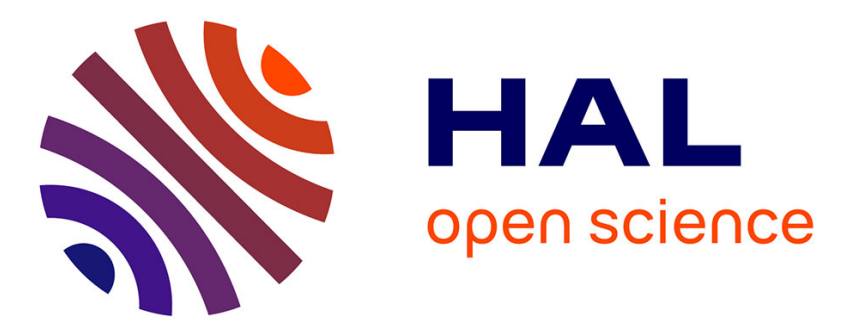

\title{
THE NONLINEAR GALERKIN METHOD APPLIED TO SHALLOW WATER EQUATIONS
}

\author{
Bernard Di Martino, F. J. Chatelon, P. Orenga
}

\section{To cite this version:}

Bernard Di Martino, F. J. Chatelon, P. Orenga. THE NONLINEAR GALERKIN METHOD APPLIED TO SHALLOW WATER EQUATIONS. Mathematical Models and Methods in Applied Sciences, 1999, Mathematical Models and Methods in Applied Sciences, 09 (06), pp.825 - 854. 10.1142/S0218202599000397 . hal-01630390

\section{HAL Id: hal-01630390 https://hal.science/hal-01630390}

Submitted on 26 Feb 2021

HAL is a multi-disciplinary open access archive for the deposit and dissemination of scientific research documents, whether they are published or not. The documents may come from teaching and research institutions in France or abroad, or from public or private research centers.
L'archive ouverte pluridisciplinaire HAL, est destinée au dépôt et à la diffusion de documents scientifiques de niveau recherche, publiés ou non, émanant des établissements d'enseignement et de recherche français ou étrangers, des laboratoires publics ou privés. 


\title{
THE NONLINEAR GALERKIN METHOD APPLIED TO SHALLOW WATER EQUATIONS
}

\author{
B. DI MARTINO, F.J. CHATELON and P. ORENGA \\ Centre de mathématique et de Calcul Scientifique \\ URA 2053, Université de Corse, Quartier Grossetti \\ 20250 Corti \\ e-mail : \{dimartin,chatelon,orenga\}@lotus.univ-corse.fr
}

\begin{abstract}
In this work, we present some numerical approximations for a shallow water problem with a depth-mean velocity formulation and we give, where possible, an error bound. To prove the existence of solutions, we build a sequence of approximated solutions with the Galerkin method for the momentum equation and we solve the continuity equation with the method of the characteristics. This leads to an expensive natural numerical scheme. Then, in order to reduce the CPU time, we present other numerical approximations based on the linear or nonlinear Galerkin method.
\end{abstract}

\section{Introduction}

\subsection{Notations}

Let $\Omega$ be a fixed bounded smooth open domain of $R^{2}$ with boundary $\gamma$. Physically, $\Omega$ is the domain corresponding to the surface of the sea assumed to be horizontal. Let $u=\left(u_{1}, u_{2}\right)$ be the mean velocity of the fluid (a vector function from $\Omega$ into $R^{2}$ ) and let $h$ be the water elevation (a scalar function from $\Omega$ into $R$ ). If $u=\left(u_{1}, u_{2}\right)$ is a vector function and $q$ is a scalar function from $\Omega$ into $R^{2}$, then we denote by

$\alpha$, the operator from $R^{2}$ into $R^{2}$ defined by

$$
\alpha(u)=\left(-u_{2}, u_{1}\right),
$$

Curl ("Curl with capital C") the operator from $R$ into $R^{2}$ defined by

$$
\operatorname{Curl} q=\left(\frac{\partial q}{\partial x_{2}},-\frac{\partial q}{\partial x_{1}}\right),
$$

curl ("curl with small c") the operator from $R^{2}$ into $R$ defined by

$$
\operatorname{curl} u=\frac{\partial u_{2}}{\partial x_{1}}-\frac{\partial u_{1}}{\partial x_{2}} .
$$


We also denote by $(\cdot, \cdot)$ the scalar product of $L^{2}(\Omega)$ and $L^{2}(\Omega)^{2}$ and by $((\cdot, \cdot))$ the scalar product of $\mathcal{V}$.

\subsection{Equations of the model}

The shallow water equations are used in the modelling of the bidimensional circulation of geophysical fluids. The equations of the model in a depth-mean velocity formulation are the following : $(P)$

$$
\begin{gathered}
\left.u_{t}+\frac{1}{2} \operatorname{grad} u^{2}+\operatorname{curl} u \alpha(u)+\omega \alpha(u)+g \operatorname{grad} h-A \Delta u=f \text { in } \Omega \times\right] 0, T[=Q, \\
h_{t}+\operatorname{div}(u h)=0 \quad \text { in } Q, \\
u \cdot n=0 \quad ; \quad \operatorname{curl} u=0 \quad \text { on } \gamma \times] 0, T[ \\
u(t=0)=u_{0}(x) \quad \text { in } Q, \\
h(t=0)=h_{0}(x) \quad \text { in } Q, h_{0} \geq 0 .
\end{gathered}
$$

For the sake of simplicity, we set $g=1$ and $\omega=1$.

\subsection{Theoretical results and numerical approximations}

(a) The linear Galerkin method and characteristics.

Firstly we recall an existence theorem for the weak solutions of this problem. This result is a global existence theorem with controlled data. We define the functional space $\mathcal{V}$ as follows :

$$
\mathcal{V}=\left\{\varphi \in L^{2}(\Omega)^{2} / \operatorname{div} \varphi \in L^{2}(\Omega), \operatorname{curl} \varphi \in L^{2}(\Omega) ; \varphi \cdot n=0 \text { on } \gamma\right\}
$$

This space is equipped with the graph-norm

$$
\|\varphi\|_{\mathcal{V}}=\|\varphi\|_{L^{2}(\Omega)}+\|\operatorname{div} \varphi\|_{L^{2}(\Omega)}+\|\operatorname{rot} \varphi\|_{L^{2}(\Omega)} .
$$

Let $(V)$ be the following weak formulation of problem $(P)$

Find

$$
u \in L^{2}(0, T ; \mathcal{V}) \cap L^{\infty}\left(0, T ; L^{2}(\Omega)^{2}\right) \quad, \quad h \in L^{\infty}\left(0, T ; L^{1}(\Omega)\right) \quad \text { and } \quad h \geq 0
$$

such that

$$
\begin{gathered}
\left(\frac{\partial u}{\partial t}, v\right)-\frac{1}{2}\left(u^{2}, \operatorname{div} v\right)+(\operatorname{curl} u \alpha(u), v)+(\alpha(u), v)+A((u, v)) \\
-(h, \operatorname{div} v)=(f, v) \quad \forall v \in \mathcal{V} \cap H^{4}(\Omega)^{2} \\
\frac{\partial h}{\partial t}+\operatorname{div}(u h)=0 \quad \text { in } L^{1}\left(0, T ; W^{-1,1}(\Omega)\right) \\
u(0, x)=u_{0}(x) \in \mathcal{V}, \quad h(0, x)=h_{0}(x) \in L^{1}(\Omega), h_{0}(x) \geq 0 \quad \text { a.e. in } \Omega .
\end{gathered}
$$

If the data are small enough, we show that $(V)$ has a solution with a fixed-point method. 
Indeed, if we denote a basis of $\mathcal{V}$ by $\left\{\varphi_{1}, \varphi_{2}, \ldots, \varphi_{m}, \ldots\right\}$, then we define $\mathcal{V}_{m}$, the set of linear combinations of the $m$ first elements of the basis. We use the Galerkin method to approximate the solution of the momentum equation (1.3) while the continuity equation (1.4) is solved with the method of characteristics.

The associated numerical method is costly in CPU time. In the following sections, we present other numerical methods in order to reduce the CPU time.

(b) Nonlinear Galerkin method and characteristics.

The first approach consists in applying the nonlinear Galerkin method to solve the momentum equation. This method, initially developped by M. Marion and R. Temam ${ }^{7}$ in the context of the Navier-Stokes equations, consists in simplifying the interaction laws between the small and large eddies. To obtain these simplifications, we write $u_{m}$ as follows :

$$
u_{m}=y_{m}+z_{m} \quad \text { with } \quad y_{m}=\sum_{i=1}^{m_{1}} x_{i}(t) \varphi(x) \text { and } z_{m}=\sum_{i=m_{1}+1}^{m} x_{i}(t) \varphi(x)
$$

and we eliminate some coupling terms between $y_{m}$ and $z_{m}$.

With this decomposition, we establish the a priori estimates, and we prove that the difference between the solution of this weak problem and $(u, h)$ is arbitrarily small.

(c) Global Galerkin method.

Since the solving of the continuity equation represents a large portion of the CPU time, we have used the Galerkin method to solve this equation. We give some convergence results to the solution $(u, h)$ of the weak problem $(V)$.

(d) Nonlinear global Galerkin method.

Finally, we apply the nonlinear Galerkin method to the momentum equation and the continuity equation. The convergence results are similar to the results obtained in the previous two steps.

(e) Numerical application.

In the last part of this paper, we present a comparison between these different numerical methods. We present, in a simple case, the CPU time and error associated with each approach.

The complexity of these numerical methods increases but the time of computation is reduced and the numerical solution has retained a good level of accuracy.

\section{Existence results for the problem $(V)$ and numerical methods}

In the first part of this section, we recall an existence theorem for the solutions of the weak problem $(V)$ when the data are small enough ${ }^{9}$. Next, we recall a theorem in order to build a special basis which is well-adapted to this problem ${ }^{8}$. Finally, we briefly recall the method of characteristics used to solve the continuity equation ${ }^{2}$ and we give the complete numerical method that we use to approximate the weak 
solutions.

\subsection{An existence theorem}

In what follows, we denote by $A, B, C, \lambda$ and $\theta$ constants such as

$$
\begin{gathered}
2 A>\lambda>0, \quad B=2 A-\lambda \\
0<\theta<1
\end{gathered}
$$

$C$ is the best constant associated with the Gagliardo Nirenberg inequality

$$
\|u\|_{L^{4}(\Omega)^{2}}^{2} \leq C\|u\|_{\mathcal{V}}\|u\|_{L^{2}(\Omega)}
$$

We obtain the following theorem

Theorem 2.1 Let $u_{0} \in \mathcal{V}, h_{0} \in L^{1}(\Omega)$ and $f$ satisfying

$$
\begin{gathered}
h_{0} \geq 0, \quad h_{0} \log h_{0} \in L^{1}(\Omega), f \in L^{2}\left(0, T ; H^{-1}(\Omega)^{2}\right), \\
\left\|u_{0}\right\|_{L^{2}(\Omega)}^{2}+2\left\|h_{0} \log h_{0}\right\|_{L^{1}(\Omega)}+\frac{1}{\lambda}\|f\|_{L^{2}\left(0, T ; H^{-1}(\Omega)\right)}^{2}+\frac{2}{e} \operatorname{mes}(\Omega)<\theta^{2} \frac{B^{2}}{C^{2}}, \\
\left\|u_{0}\right\|_{L^{2}(\Omega)}<\theta \frac{B}{C} .
\end{gathered}
$$

Then, for each $\theta, \lambda, f, u_{0}, h_{0}$ satisfying (2.7), (2.8), (2.10),(2.11),(2.12), the problem $(V)$ has a solution $(u, h)$ such that

$$
(u, h) \in\left\{\left[L^{2}(0, T ; \mathcal{V}) \cap L^{\infty}\left(0, T ; L^{2}(\Omega)^{2}\right)\right] \times L^{\infty}\left(0, T ; L^{1}(\Omega)\right)\right\} .
$$

Moreover the solution satisfies

$$
\begin{gathered}
\|u\|_{L^{\infty}\left(0, T ; L^{2}(\Omega)^{2}\right)}^{2} \leq \theta^{2} \frac{B^{2}}{2 C^{2}}+\frac{2}{e} \operatorname{mes}(\Omega), \\
\|u\|_{L^{2}(0, T ; \mathcal{V})}^{2} \leq \frac{\theta^{2} B^{2}}{C^{2}(B-C)}+\frac{2}{e} \operatorname{mes}(\Omega), \\
-\frac{1}{e} \operatorname{mes}(\Omega) \leq \sup _{t} \int_{\Omega} h \log h \leq \theta^{2} \frac{B^{2}}{2 C^{2}}, \quad h \geq 0 .
\end{gathered}
$$

A detailed proof of this theorem is given in ${ }^{9}$.

\subsection{Special basis}

We now provide a theorem in order to build a special basis of the space $\mathcal{V}(1.1)$, satisfying the impermeability boundary conditions.

We consider the following eigen problem (P1)

$$
\mid \begin{array}{ll}
-\Delta u=\lambda u & \text { in } \Omega \\
u \cdot n=\operatorname{curl} u=0 & \text { on } \gamma
\end{array}
$$




\section{Theorem 2.2}

- If $(\lambda, p)$ is a solution to the scalar problem

$$
\text { (P2) } \quad-\Delta p=\lambda p \text { in } \Omega, \frac{\partial p}{\partial n}=0 \text { on } \gamma \text {; }
$$

then $(\lambda, \operatorname{grad} p)$ is a solution of (P1).

- If $(\mu, q)$ is a solution to the scalar problem

$$
\text { (P3) }-\Delta q=\mu q \text { in } \Omega, q=0 \text { on } \gamma \text {; }
$$

then $(\mu, \operatorname{Curl} q)$ is a solution of (P1).

- If $\Omega$ is simply connected, then 0 is not an eigen value of (P1), otherwise the eigen space associated to 0 is the finite dimensional space $H_{0}(\operatorname{div} 0, \operatorname{curl} 0)$ where

$H_{0}(\operatorname{div} 0, \operatorname{curl} 0)=\left\{u \in L^{2}(\Omega)^{2}, \operatorname{div} u=0, \operatorname{curl} u=0, u \cdot n=0\right.$ on $\left.\gamma\right\}$.

- The set composed of $\operatorname{grad} p$ and $\operatorname{Curl} q$, where $p$ is solution of (P2) and $q$ is solution of (P3), is a total basis in $L^{2}(\Omega)^{2} \backslash H_{0}(\operatorname{div} 0, \operatorname{curl} 0)$ and in $\mathcal{V} \backslash$ $H_{0}(\operatorname{div} 0, \operatorname{curl} 0)$.

- If $\Omega$ is a smooth domain, then we obtain $\mathcal{V}=\left\{\varphi \in H^{1}(\Omega)^{2}, \varphi \cdot n=0\right\}$ and the solutions of problem (P1) are very smooth.

Moreover, the set composed of the functions $p_{i}$, solutions of (P2), constitute an orthogonal basis of $L^{2}(\Omega)$.

\subsection{The numerical method}

Let $\left\{\varphi_{1}, \ldots, \varphi_{m}, \ldots\right\}$ be a basis of $\mathcal{V}$, the functions $\varphi_{i}$ belong to $H^{4}(\Omega)^{2}$ and satisfy the relationship

$$
\begin{gathered}
-\Delta \varphi_{i}=\lambda_{i} \varphi_{i}, \\
0<\lambda_{1} \leq \lambda_{2} \leq \ldots, \lambda_{j} \rightarrow \infty \text { when } j \rightarrow \infty .
\end{gathered}
$$

We denote by $\mathcal{V}_{m}$ the set of the linear combinations of the $m$ first functions $\left\{\varphi_{1}, \ldots, \varphi_{m}\right\}$ and we are looking for $u_{m} \in \mathcal{V}_{m}$ where $u_{m}$ is of the form

$$
u_{m}(x, t)=\sum_{i=1}^{m} x_{i}(t) \varphi_{i}(x)
$$

and we build the sequence $\left(u_{m}, h_{m}\right)$, solution to the following problem $\left(V_{m}\right)$ :

Find $\left(u_{m}, h_{m}\right) \in\left(L^{\infty}\left(0, T ; L^{2}(\Omega)^{2}\right) \cap L^{2}(0, T ; V)\right) \times L^{\infty}\left(0, T ; L^{1}(\Omega)\right)$ such that

$$
\begin{gathered}
\left(\frac{\partial u_{m}}{\partial t}, \varphi_{i}\right)-\frac{1}{2}\left(u_{m}^{2}, \operatorname{div} \varphi_{i}\right)+\left(\operatorname{curl} u_{m} \alpha\left(u_{m}\right), \varphi_{i}\right)+\left(\alpha\left(u_{m}\right), \varphi_{i}\right) \\
+A\left(\left(u_{m}, \varphi_{i}\right)\right)-\left(h_{m}, \operatorname{div} \varphi_{i}\right)=\left(f, \varphi_{i}\right) \quad \forall \varphi_{i}, i=1, \ldots, m \\
\frac{\partial h_{m}}{\partial t}+\operatorname{div}\left(u_{m} h_{m}\right)=0 \\
u_{m}(t=0)=u_{0 m} \in \mathcal{V}_{m}, \quad h_{m}(t=0)=h_{0 m} \in C^{1}(\bar{\Omega})
\end{gathered}
$$


where the constants and the data satisfy the conditions of Theorem 2.1.

If $h_{0 m} \in C^{1}(\bar{\Omega})$, then we have proven in ${ }^{3}$ that $\left(u_{m}, h_{m}\right) \in C^{0}\left([0, T] ; C^{2}(\bar{\Omega})\right) \times$ $C^{1}(\bar{Q})$.

The properties of the basis allow us to write the nonlinear terms in a simpler fashion and we obtain a system with $m$ differential equations of the form:

$$
\frac{d x_{i}}{d t}=F_{i}\left(x_{j}, x_{k}\right)+G_{i}\left(h_{m}\right),
$$

where the functions $F_{i}$ are integrals of basis function products. We need only compute these integrations once for a given domain. The term $G_{i}$ is the projection of the water elevation gradient on the basis elements. We need to know this term for each time step, after computation of the water elevation.

To compute the water elevation, we use the method of characteristics. We evaluate the variations in water elevation on a trajectory. We recall that

$$
u_{1}=\frac{d x_{1}}{d t} \quad ; \quad u_{2}=\frac{d x_{2}}{d t} .
$$

Thus, we can write the continuity equation (2.18) of the form

$$
\frac{D h_{m}}{D t}=-h_{m} \operatorname{div} u_{m}
$$

where $\frac{D h_{m}}{D t}$ is the time derivative of $h_{m}(x(t), t)$ as $x(t)$ moves along with the fluid at velocity $u_{m}$. Therefore let $X\left(t_{i-1}\right)$ denote the position of a particle of fluid at time $t_{i-1}$ which will be in $x$ at time $t_{i-1}+\triangle t$ ( $\triangle t$ is the time step). Then (2.21) may be approximated by

$$
h_{m}\left(X\left(t_{i}\right), t_{i}\right)=h_{m}\left(X\left(t_{i-1}\right), t_{i-1}\right) \exp \left(-\triangle t \operatorname{div} u_{m}\left(X\left(t_{i}\right), t_{i}\right)\right)
$$

Note that on each point, there is a unique characteristic curve. If we have the boundary condition $u . n \neq 0$, it is necessary to prescribe the water elevation on the part of the boundary where the flow enters.

This method is well-adapted to both the problem and the theoretical results. The CPU time, however,is very important. In what follows, we therefore present some new approaches in order to reduce this simulation time.

\section{Nonlinear Galerkin method}

In this section, we apply the nonlinear Galerkin method to the resolution of the momentum equation. In this work, we adapt the results obtained by M. Marion and R. Temam on the Navier-Stokes equations ${ }^{7}$.

\subsection{Description of the method}

In what follows, we consider $m \in N, m_{1} \in N$ and we suppose $m>m_{1}$. 
We denote by $\mathcal{V}_{m_{1}}$ the space generated by the $m_{1}$ first $\varphi_{i}$ functions and by $\tilde{\mathcal{V}}_{m_{1}}$ the space generated by the next $m-m_{1} \varphi_{i}$ functions.

We set

$$
u_{m}=y_{m}+z_{m} \quad \text { with } \quad y_{m}=\sum_{i=1}^{m_{1}} x_{i}(t) \varphi_{i}(x) \text { and } z_{m}=\sum_{i=m_{1}+1}^{m} x_{i}(t) \varphi_{i}(x)
$$

and we denote by $\left(V_{m}^{a}\right)$ the following approximate problem:

$$
\begin{gathered}
\left(\frac{\partial y_{m}}{\partial t}, \varphi_{i}\right)-\frac{1}{2}\left(y_{m}^{2}, \operatorname{div} \varphi_{i}\right)-\left(y_{m} z_{m}, \operatorname{div} \varphi_{i}\right) \\
+\left(\operatorname{curl} y_{m} \alpha\left(y_{m}\right), \varphi_{i}\right)+\left(\operatorname{curl} z_{m} \alpha\left(y_{m}\right), \varphi_{i}\right)+\left(\operatorname{curl} y_{m} \alpha\left(z_{m}\right), \varphi_{i}\right) \\
+\left(\alpha\left(y_{m}\right), \varphi_{i}\right)+\left(\alpha\left(z_{m}\right), \varphi_{i}\right) \\
+A\left(\left(y_{m}, \varphi_{i}\right)\right)-\left(h_{m}, \operatorname{div} \varphi_{i}\right)=\left(f, \varphi_{i}\right) \quad \forall \varphi_{i} \in \mathcal{V}_{m_{1}}, i=1, \ldots, m_{1} \\
\left(\frac{\partial z_{m}}{\partial t}, \varphi_{i}\right)-\frac{1}{2}\left(y_{m}^{2}, \operatorname{div} \varphi_{i}\right)+\left(\operatorname{curl} y_{m} \alpha\left(y_{m}\right), \varphi_{i}\right) \\
+\left(\alpha\left(y_{m}\right), \varphi_{i}\right)+A\left(\left(z_{m}, \varphi_{i}\right)\right) \\
-\left(h_{m}, \operatorname{div} \varphi_{i}\right)=\left(f, \varphi_{i}\right) \forall \varphi_{i} \in \tilde{\mathcal{V}}_{m_{1}}, i=m_{1}+1, \ldots, m \\
\frac{\partial h_{m}}{\partial t}+\operatorname{div}\left(y_{m} h_{m}\right)+\operatorname{div}\left(z_{m} h_{m}\right)=0 \\
y_{m}(t=0)=\mathcal{P}_{m_{1}}\left(u_{0}\right)=y_{0 m} \in \mathcal{V}_{m_{1}} \\
z_{m}(t=0)=\tilde{\mathcal{P}}_{m_{1}}\left(u_{0}\right)=z_{0 m} \in \tilde{\mathcal{V}}_{m_{1}} \text { and } h_{0 m} \in C^{1}(\bar{\Omega})
\end{gathered}
$$

where $\mathcal{P}_{m_{1}}$ denotes the $L^{2}$-projection operator on the space $\mathcal{V}_{m_{1}}$ and $\tilde{\mathcal{P}}_{m_{1}}$ denotes the $L^{2}$-projection operator on the space $\tilde{\mathcal{V}}_{m_{1}}$.

The continuity equation is solved using the method of the characteristics as previously described.

\subsection{Existence and convergence results}

We give an existence result for the solutions to problem $\left(V_{m}^{a}\right)$ with convergence results.

Theorem 3.3 All the constants are defined as in Theorem 2.1, except for B, which is defined by $B=\left(A-\frac{\lambda}{2}\right) / \sqrt{2}$.

Let $y_{0 m} \in \mathcal{V}_{m_{1}}, z_{0 m} \in \tilde{\mathcal{V}}_{m_{1}}, h_{0 m} \in C^{1}(\bar{\Omega})$ and $f \in L^{2}\left(0, T, H^{-1}(\Omega)^{2}\right)$ satisfying

$$
h_{0 m} \geq 0, h_{0 m} \log h_{0 m} \in L^{1}(\Omega)
$$




$$
\begin{gathered}
\left\|y_{0 m}+z_{0 m}\right\|_{L^{2}(\Omega)}^{2}+\left\|h_{m}(0) \log h_{m}(0)\right\|_{L^{1}(\Omega)}+\frac{1}{\lambda}\|f\|_{L^{2}\left(0, T ; H^{-1}(\Omega)^{2}\right)}^{2} \\
+\frac{2}{e} \operatorname{mes}(\Omega)<\theta\left(\frac{B}{C}\right)^{2}, \\
\left\|y_{0 m}+z_{0 m}\right\|_{L^{2}(\Omega)}<\theta \frac{B}{C} .
\end{gathered}
$$

Then:

$$
\begin{gathered}
z_{m} \rightarrow 0 \text { weakly in } L^{2}(0, T ; \mathcal{V}) \\
z_{m} \rightarrow 0 \text { strongly in } L^{2}\left(0, T ; L^{2}(\Omega)^{2}\right) \\
y_{m} \rightarrow u^{*} \text { weakly in } L^{2}(0, T ; \mathcal{V}) \text { and weakly in } L^{\infty}\left(0, T ; L^{2}(\Omega)^{2}\right)-* \\
\int_{Q} h_{m} \Theta d x d t \rightarrow \int_{Q} h \Theta d x d t \text { for each } \Theta \in L^{1}\left(0, T ; L^{\infty}(\Omega)\right) \\
\frac{\partial y_{m}}{\partial t} \text { bounded in } L^{2}\left(0, T ; H^{-3}(\Omega)^{2}\right) \\
\left(\operatorname{curl} y_{m} \alpha\left(z_{m}\right), \varphi\right)_{L^{2}(\Omega)^{2}} \rightarrow 0 \text { strongly in } L^{1}(0, T) \\
\left(\operatorname{curl} z_{m} \alpha\left(y_{m}\right), \varphi\right)_{L^{2}(\Omega)^{2}} \rightarrow 0 \text { strongly in } L^{1}(0, T) \\
\left(y_{m} z_{m}, \operatorname{div} \varphi\right)_{L^{2}(\Omega)^{2}} \rightarrow 0 \text { strongly in } L^{1}(0, T) \\
\left(y_{m}+z_{m}\right) h_{m} \rightarrow u h \text { strongly in } L^{1}(Q)
\end{gathered}
$$

Proof. First, we give the a priori estimates satisfied by the solution of $\left(V_{m}^{a}\right)$. Then we pass to the limit and we prove that $\left(y_{m}, h_{m}\right)$ converges to the solution $(u, h)$ of $(V)$.

(i) a priori estimates

We set $y_{m}=\varphi_{i}$ in (3.24), $z_{m}=\varphi_{i}$ in (3.26), and we add these two equations. Noting that

$$
(\alpha(u), v)+(\alpha(v), u)=0
$$

and

$$
(\operatorname{curl} u \alpha(u), v)+(\operatorname{curl} u \alpha(v), u)=0
$$

we obtain

$$
\begin{aligned}
\frac{1}{2} \frac{\mathrm{d}}{\mathrm{d} t}\left\|u_{m}\right\|_{L^{2}(\Omega)}^{2}+A\left|u_{m}\right|_{\mathcal{V}}^{2}-\frac{1}{2}\left(y_{m}^{2}, \operatorname{div} u_{m}\right) \\
\quad-\left(y_{m} z_{m}, \operatorname{div} y_{m}\right)-\left(h_{m}, \operatorname{div} u_{m}\right)=\left(f, u_{m}\right) .
\end{aligned}
$$

The right hand side in (3.38) is bounded by

$$
\left(f, u_{m}\right) \leq \frac{1}{2 \lambda}\|f\|_{H^{-1}(\Omega)}^{2}+\frac{\lambda}{2}\left|u_{m}\right|_{\mathcal{V}}^{2} .
$$


The term $\left(h_{m}, \operatorname{div} u_{m}\right)$ is estimated as $\operatorname{in}^{9}$. We thus obtain

$$
\left(h_{m}, \operatorname{div} u_{m}\right)=\frac{d}{d t}\left(h_{m} \log h_{m}-h_{m}, 1\right) .
$$

The other terms which are not necessarily bounded are the nonlinear terms. To estimate these terms, we build a stability space. We obtain

$$
\begin{gathered}
\frac{1}{2}\left(y_{m}^{2}, \operatorname{div} u_{m}\right) \leq \frac{C}{2}\left\|y_{m}\right\|_{L^{2}(\Omega)}\left\|y_{m}\right\|_{\mathcal{V}}\left\|u_{m}\right\|_{\mathcal{V}} \\
\left(y_{m} z_{m}, \operatorname{div} y_{m}\right) \leq C\left\|y_{m}\right\|_{L^{2}(\Omega)}^{1 / 2}\left\|y_{m}\right\|_{\mathcal{V}}^{1 / 2}\left\|z_{m}\right\|_{L^{2}(\Omega)}^{1 / 2}\left\|z_{m}\right\|_{\mathcal{V}}^{1 / 2}\left\|u_{m}\right\|_{\mathcal{V}}
\end{gathered}
$$

Then, adding the two inequalities, we obtain

$$
\begin{aligned}
& \frac{1}{2}\left(y_{m}^{2}, \operatorname{div} u_{m}\right)+\left(y_{m} z_{m}, \operatorname{div} y_{m}\right) \\
& \quad \leq C\left\|y_{m}\right\|_{L^{2}(\Omega)}^{1 / 2}\left\|y_{m}\right\|_{\mathcal{V}}^{1 / 2}\left\|u_{m}\right\|_{\mathcal{V}}\left[\frac{1}{2}\left\|y_{m}\right\|_{L^{2}(\Omega)}^{1 / 2}\left\|y_{m}\right\|_{\mathcal{V}}^{1 / 2}+\left\|z_{m}\right\|_{L^{2}(\Omega)}^{1 / 2}\left\|z_{m}\right\|_{\mathcal{V}}^{1 / 2}\right] \\
& \quad \leq C\left\|y_{m}\right\|_{L^{2}(\Omega)}^{1 / 2}\left\|y_{m}\right\|_{\mathcal{V}}^{1 / 2}\left\|u_{m}\right\|_{\mathcal{V}}\left[\left\|y_{m}\right\|_{L^{2}(\Omega)}^{1 / 2}\left\|y_{m}\right\|_{\mathcal{V}}^{1 / 2}+\left\|z_{m}\right\|_{L^{2}(\Omega)}^{1 / 2}\left\|z_{m}\right\|_{\mathcal{V}}^{1 / 2}\right] \\
& \quad \leq C\left\|y_{m}\right\|_{L^{2}(\Omega)}^{1 / 2}\left|u_{m}\right|_{\mathcal{V}}^{2}\left[\left\|y_{m}\right\|_{L^{2}(\Omega)}^{1 / 2}+\left\|z_{m}\right\|_{L^{2}(\Omega)}^{1 / 2}\right] \\
& \quad \leq \sqrt{2} C\left\|u_{m}\right\|_{L^{2}(\Omega)}\left|u_{m}\right|_{\mathcal{V}}^{2}
\end{aligned}
$$

and finally

$$
\begin{aligned}
\frac{1}{2} \frac{\mathrm{d}}{\mathrm{d} t}\left\|u_{m}\right\|_{L^{2}(\Omega)}^{2}+\mid & \left.u_{m}\right|_{\mathcal{V}} ^{2}\left[\left(A-\frac{\lambda}{2}\right)-\sqrt{2} C\left\|u_{m}\right\|_{L^{2}(\Omega)}\right] \\
+ & \frac{d}{d t}\left(h_{m} \log h_{m}-h_{m}, 1\right) \leq \frac{1}{2 \lambda}\|f\|_{H^{-1}(\Omega)}^{2} .
\end{aligned}
$$

To obtain the a priori estimates, we choose the data such that

$$
\left(A-\frac{\lambda}{2}\right)-\sqrt{2} C\left\|u_{m}\right\|_{L^{2}(\Omega)}>0
$$

Thus, setting $B=\left(A-\frac{\lambda}{2}\right) / \sqrt{2}$ :

$$
\left\|u_{m}(t)\right\|_{L^{2}(\Omega)}<\frac{B}{C} \quad \forall t .
$$

To prove this result, we use the same arguments as in ${ }^{9}$.

We deduce that $u_{m}$ is bounded in $L^{\infty}\left(0, T ; L^{2}(\Omega)\right) \cap L^{2}(0, T ; \mathcal{V})$.

Since $z_{m}$ is bounded in $L^{2}(0, T ; \mathcal{V})$ for each $T>0$, and, by constructing $\left\|z_{m}\right\|_{L^{2}(0, T ; \mathcal{V})} \geq \lambda_{m_{1}+1}^{1 / 2}\left\|z_{m}\right\|_{L^{2}(\Omega)}^{2}$, we then obtain

$$
\forall T>0, \quad \lambda_{m_{1}+1}^{1 / 2} z_{m} \text { is bounded in } L^{2}\left(0, T ; L^{2}(\Omega)\right) .
$$


Finally, we give some results on the nonlinear terms. Since $y_{m}$ and $z_{m}$ are both bounded in $L^{2}(0, T ; \mathcal{V})$, then $\operatorname{curl} y_{m}$ and $\operatorname{curl} z_{m}$ are bounded in $L^{2}(Q)$. Moreover, $y_{m}$ and $z_{m}$ are also bounded in $L^{4}(Q)$. Therefore, curl $y_{m} \alpha\left(y_{m}\right)$, $\operatorname{curl} z_{m} \alpha\left(y_{m}\right)$ and $\operatorname{curl} y_{m} \alpha\left(z_{m}\right)$ are bounded in $L^{\frac{4}{3}}(Q)$.

Similarly, we obtain $\operatorname{grad} y_{m}^{2}$ and $\operatorname{grad}\left(y_{m} z_{m}\right)$ bounded in $L^{\frac{4}{3}}(Q)$.

(ii) Passage to the limit

Since $\lambda_{m} \rightarrow \infty$ as $m \rightarrow \infty$, (3.41) leads to

$$
\forall T>0, \quad z_{m} \rightarrow 0 \text { strongly in } L^{2}\left(0, T ; L^{2}(\Omega)\right) \text { as } m \rightarrow+\infty .
$$

Moreover $z_{m}$ is bounded in $L^{2}(0, T ; \mathcal{V})$ for each $T>0$ and the uniqueness of the limit gives

$$
\forall T>0, \quad z_{m} \rightarrow 0 \text { weakly in } L^{2}(0, T ; \mathcal{V}) \text { as } m \rightarrow+\infty .
$$

As $y_{m}$ is bounded in $L^{\infty}\left(0, T ; L^{2}(\Omega)^{2}\right) \cap L^{2}(0, T ; \mathcal{V})$, then $u^{*}$ exists such that : $\forall T>0$,

$$
y_{m} \rightarrow u^{*} \text { weakly in } L^{2}(0, T ; \mathcal{V}) \text { and weakly in } L^{\infty}\left(0, T ; L^{2}(\Omega)^{2}\right)-*
$$

To pass to the limit in the nonlinear terms, we need a strong convergence in $L^{2}(Q)$ for $y_{m}$ and $z_{m}$. This result is obtained with the Aubin theorem. In order to apply this compacity theorem, we must have a smoothness result for $\frac{\partial y_{m}}{\partial t}$.

Indeed, $\frac{\partial y_{m}}{\partial t}$ is as smooth as $\nabla h_{m}$ which is the least smooth term. But $h_{m} \in L^{1}(\Omega)$ and $L^{1}(\Omega) \hookrightarrow C^{0, \alpha}(\Omega)$ continuously. In a two dimensional space, the embedding of $H^{2}(\Omega)$ in $C^{0, \alpha}(\Omega)$ is continuous, and by duality, $L^{1}(\Omega) \hookrightarrow$ $H^{-2}(\Omega)$ continuously. Thus $h_{m} \in L^{2}\left(0, T ; H^{-2}(\Omega)\right)$. We obtain

$$
\frac{\partial y_{m}}{\partial t} \text { bounded in } L^{2}\left(0, T ; H^{-3}(\Omega)^{2}\right) \text {. }
$$

By applying the Aubin theorem, we therefore prove that $y_{m}$ converges strongly a.e. to $u^{*}$ in $L^{2}\left(0, T ; L^{2}(\Omega)^{2}\right)$.

We pass to the limit in the terms grad $y_{m}^{2}$ and $\operatorname{curl} y_{m} \alpha\left(y_{m}\right)$ as in ${ }^{9}$. Indeed, $\forall \varphi \in D(Q)$

$$
\begin{aligned}
& \left|\left(\operatorname{curl} y_{m} \alpha\left(y_{m}\right)-\operatorname{curl} u^{*} \alpha\left(u^{*}\right), \varphi\right)_{L^{2}(Q)}\right| \\
& \quad \leq\left|\left(\operatorname{curl} y_{m} \alpha\left(y_{m}-u^{*}\right), \varphi\right)_{L^{2}(Q)}\right|+\left|\left(\left(\operatorname{curl} y_{m}-\operatorname{curl} u^{*}\right) \alpha\left(u^{*}\right), \varphi\right)_{L^{2}(Q)}\right| \\
& \quad \leq \mid \operatorname{curl} y_{m}\left\|_{L^{2}(Q)}\right\| y_{m}-u^{*}\left\|_{L^{2}(Q)}\right\| \varphi \|_{L^{\infty}(Q)} \\
& \quad+\left|\left(\left(\operatorname{curl} y_{m}-\operatorname{curl} u^{*}\right), u^{*} \varphi\right)_{L^{2}(Q)}\right|
\end{aligned}
$$

$\operatorname{curl} y_{m} \alpha\left(y_{m}\right)$ then converges weakly to $\operatorname{curl} u^{*} \alpha\left(u^{*}\right)$ in $D^{\prime}(Q)$. Owing to the uniqueness of the limit, $\operatorname{curl} y_{m} \alpha\left(y_{m}\right)$ converges weakly to $\operatorname{curl} u^{*} \alpha\left(u^{*}\right)$ in $L^{\frac{4}{3}}(Q)$. 
In the same way, we can show that $\operatorname{grad} y_{m}^{2}$ converges weakly to $\operatorname{grad} u^{* 2}$ in $L^{\frac{4}{3}}(Q)$.

Now we must pass to the limit in the nonlinear terms coupling $y_{m}$ and $z_{m}$. We obtain

$$
\begin{aligned}
\int_{0}^{T}\left|\left(\operatorname{curl} y_{m} \alpha\left(z_{m}\right), \varphi\right)_{L^{2}(\Omega)^{2}}\right| & \leq \int_{0}^{T}\left\|y_{m}\right\|_{\mathcal{V}}\left\|z_{m}\right\|_{L^{2}(\Omega)}^{2}\|\varphi\|_{L^{\infty}(\Omega)^{2}} \\
& \leq\left\|y_{m}\right\|_{L^{2}(0, T ; \mathcal{V})}\left\|z_{m}\right\|_{L^{2}(Q)}\|\varphi\|_{L^{\infty}(Q)}
\end{aligned}
$$

As $z_{m}$ converges strongly to 0 in $L^{2}(Q)$, we conclude that $\forall T>0$,

$$
\left(\operatorname{curl} y_{m} \alpha\left(z_{m}\right), \varphi\right)_{L^{2}(\Omega)^{2}} \rightarrow 0 \text { strongly in } L^{1}(0, T) \text { as } m \rightarrow \infty \text {. }
$$

In the same way, we have

$$
\int_{0}^{T}\left(\operatorname{curl} z_{m} \alpha\left(y_{m}\right), \varphi\right)_{L^{2}(\Omega)^{2}}=\int_{0}^{T}\left(\operatorname{curl} z_{m}, \varphi y_{m}\right)_{L^{2}(\Omega)^{2}} .
$$

Since $\forall \varphi \in L^{\infty}(\Omega), y_{m} \varphi \in L^{2}(\Omega)$ we obtain

$\forall T>0, \quad\left(\operatorname{curl} z_{m} \alpha\left(y_{m}\right), \varphi\right)_{L^{2}(\Omega)^{2}} \rightarrow 0$ strongly in $L^{1}(0, T)$ as $m \rightarrow \infty$.

We obtain a similar result for the term $\left(y_{m} z_{m}, \operatorname{div} \varphi\right)_{L^{2}(\Omega)^{2}}$.

The last point to be proved is that we can make sense to $u^{*}(t=0)$ and that $u^{*}(t=0)$ is equal to $u(t=0)$. In order to do this, we use the result

$$
\frac{\partial u^{*}}{\partial t} \in L^{\frac{4}{3}}\left(0, T ; H^{-3}(\Omega)^{2}\right) \text { and } u^{*} \in L^{2}\left(0, T ; L^{2}(\Omega)\right) \subset L^{\frac{4}{3}}\left(0, T ; H^{-3}(\Omega)^{2}\right),
$$

which proves that $u^{*}$ is continuous from $[0, T]$ in $H^{-3}(\Omega)^{2}$. Then, we make sense to $u^{*}(t=0)$ in $H^{-3}(\Omega)^{2}$; moreover $y_{m}(t=0)$ is equal to $u_{0 m_{1}}$ and $u_{0 m_{1}}$ converges to $u_{0}$ in $\mathcal{V}$. We deduce that $u^{*}(t=0)=u_{0}$.

Now, we have to pass to the limit in the continuity equation. We recall a result proved in ${ }^{9}$

Lemma 3.1 Assume that

$$
\begin{gathered}
u_{m} \in L^{2}\left(0, T, H^{m}(\Omega)^{2}\right), m \geq 3, \\
u_{m} \text { bounded in } L^{2}(0, T, \mathcal{V}), \\
h_{m} \geq 0 \text { bounded in } L^{\infty}\left(0, T ; L^{1}(\Omega)\right), \\
h_{m} \log h_{m} \text { bounded in } L^{\infty}\left(0, T ; L^{1}(\Omega)\right), \\
\frac{\partial h_{m}}{\partial t}+\operatorname{div}\left(u_{m} h_{m}\right)=0,
\end{gathered}
$$


then,

$$
\begin{gathered}
\int_{Q} h_{m} \theta d x d t \rightarrow \int_{Q} h^{*} \Theta d x d t \text { for each } \Theta \in L^{1}\left(0, T ; L^{\infty}(\Omega)\right) \\
u_{m} h_{m} \rightarrow u^{*} h^{*} \text { weakly in } L^{1}\left(0, T ; L^{1}(\Omega)^{2}\right) .
\end{gathered}
$$

Setting $u_{m}=y_{m}+z_{m}$, we show that :

$$
\left(y_{m}+z_{m}\right) h_{m} \rightarrow u^{*} h^{*} \text { weakly in } L^{1}(Q) .
$$

Now it is possible to pass to the limit in the system constituted by equations (3.24) to (3.28). We find that $u^{*}$ and $h^{*}$ satisfy the following problem:

$$
\begin{gathered}
\left(\frac{\partial u^{*}}{\partial t}, \varphi_{i}\right)-\frac{1}{2}\left(u^{* 2}, \operatorname{div} \varphi_{i}\right)+\left(\operatorname{curl} u^{*} \alpha\left(u^{*}\right), \varphi_{i}\right)+\left(\alpha\left(u^{*}\right), \varphi_{i}\right) \\
+A\left(\left(u^{*}, \varphi_{i}\right)\right)-\left(h^{*}, \operatorname{div} \varphi_{i}\right)=\left(f, \varphi_{i}\right) \forall \varphi_{i} \in \mathcal{V} \\
\frac{\partial h^{*}}{\partial t}+\operatorname{div}\left(u^{*} h^{*}\right)=0
\end{gathered}
$$

and $u^{*}(t=0)=u_{0}, h^{*}(t=0)=h_{0}$.

Thus $\left(u^{*}, h^{*}\right)$ is the unique solution of problem $(V)$.

\subsection{Numerical resolution method}

The numerical resolution of this problem and the numerical method presented in section 2.1 are nearly identical. The only difference in these two methods resides in the treatment of the unknowns associated with the large and small velocity components. Indeed, we always obtain

$$
\frac{d x_{i}}{d t}=F_{i}\left(x_{j}, x_{k}\right)+G_{i}
$$

for the velocity component $y_{m}$, but we have

$$
\frac{d x_{i}}{d t}=\tilde{F}_{i}\left(x_{j}, x_{k}\right)+G_{i}
$$

for the velocity component $z_{m}$ where $\tilde{F}_{i}$ is simpler than $F_{i}$.

The continuity equation is solved as above using the method of the characteristics.

\section{Global Galerkin method}

In this section, we use the linear Galerkin method to solve the momentum and continuity equations. Then, the continuity equation is not quite verified. We do not have the estimate $h \log h$ bounded in $L^{\infty}\left(0, T ; L^{1}(\Omega)\right)$. However, as the existence 
of the solutions to problem $V$ has been proven, we show that the approximated problem has a solution and we can obtain some convergence results of this solution to $(u, h)$ solution of $V$.

\subsection{Description of the method}

Let $\left\{p_{1}, \ldots, p_{n}, \ldots\right\}$ be a basis of $H^{1}(\Omega)$ satisfying the following relation

$$
\begin{gathered}
-\Delta p_{i}=\mu_{i} p_{i} \\
0<\mu_{1} \leq \mu_{2} \leq \ldots, \mu_{j} \rightarrow \infty \text { as } j \rightarrow \infty
\end{gathered}
$$

We denote by $H^{1}(\Omega)_{m}$ the subspace of $H^{1}(\Omega)$ generated by the $m$ first functions $\left\{p_{1}, p_{2}, \ldots, p_{m}\right\}$ and

$$
u_{m, n}(x, t)=\sum_{i=1}^{m} x_{i}(t) \varphi_{i}(x) \quad h_{m, n}(x, t)=\sum_{k=1}^{n} y_{k}(t) p_{k}(x)
$$

where $\left(u_{m, n}, h_{m, n}\right)$ is a solution of the weak problem $\left(V_{m, n}\right)$

$$
\begin{gathered}
\left(\frac{\partial u_{m, n}}{\partial t}, \varphi_{i}\right)-\frac{1}{2}\left(u_{m, n}^{2}, \operatorname{div} \varphi_{i}\right)+\left(\operatorname{curl} u_{m, n} \alpha\left(u_{m, n}\right), \varphi_{i}\right)+A\left(\left(u_{m, n}, \varphi_{i}\right)\right) \\
-\left(h_{m, n}, \operatorname{div} \varphi_{i}\right)=\left(f, \varphi_{i}\right) \quad \text { in } Q, \forall \varphi_{i}, i=1, \ldots, m(4.59) \\
\left(\frac{\partial h_{m, n}}{\partial t}, p_{i}\right)+\left(\operatorname{div}\left(u_{m, n} h_{m, n}\right), p_{i}\right)=0 \quad \text { in } Q, \forall p_{i}, i=1, \ldots, n \\
u_{m, n}(t=0)=u_{0 m n} \in \mathcal{V}_{m} \text { and } h_{m, n}(t=0)=h_{0 m n} \in H^{1}(\Omega)_{n} .
\end{gathered}
$$

\subsection{Weak convergence results}

If $\varepsilon_{1}$ is a non-negative constant, then we obtain the following result:

Theorem 4.4 The different constants are defined in the same way as in Theorem 2.1, except for constant $B$, which is defined by $B=2 A-\lambda-2 \varepsilon$, with $\varepsilon>0$.

Let $u_{0 m n} \in \mathcal{V}_{m}, h_{0 m n} \in H^{1}(\Omega)_{n}$ and $f \in L^{2}\left(0, T, H^{-1}(\Omega)^{2}\right)$ satisfying

$$
\begin{gathered}
\frac{2}{\lambda}\|f\|_{L^{2}\left(0, T ; H^{-1}(\Omega)\right)}^{2}+\left\|u_{0 m n}\right\|_{L^{2}(\Omega)}^{2}+4 \varepsilon_{1} \leq \theta\left(\frac{B}{C}\right)^{2} \\
\left\|u_{0 m n}\right\|_{L^{2}(\Omega)} \leq \theta\left(\frac{B}{C}\right)
\end{gathered}
$$

Then

- $\left(u_{m, n}, h_{m, n}\right)$ solution to $\left(V_{m, n}\right)$ converges weakly to $\left(u_{m}, h_{m}\right)$, solution to the problem $\left(V_{m}\right)$, in $L^{2}\left(0, T ; L^{q}(\Omega)\right), q<2$.

- For each $m$, there exists $n(m)$, such that $\left(u_{m, n(m)}, h_{m, n(m)}\right)$ converges to $(u, h)$, solution to $(V)$, in $L^{1}(Q) \times L^{1}(Q)$. 
The proof of this theorem is given in three steps

- Estimate of $h_{m, n}$ in relation to $u_{m, n}$.

- Estimates in the momentum equation.

- Passage to the limit in the two equations.

\section{Proof.}

(i) Estimate of $h_{m, n}$ in relation to $u_{m, n}$

We change $p_{i}$ by $h_{m, n}$ in equation (4.60). It then follows that

$$
\int_{\Omega} \frac{\partial h_{m, n}}{\partial t} h_{m, n}+\int_{\Omega} h_{m, n} \operatorname{div}\left(u_{m, n} h_{m, n}\right)=0,
$$

hence

$$
\int_{\Omega} \frac{\partial h_{m, n}^{2}}{\partial t}+\int_{\Omega} h_{m, n}^{2} \operatorname{div}\left(u_{m, n}\right)=0
$$

therefore

$$
\frac{\mathrm{d}}{\mathrm{d} t}\left\|h_{m, n}\right\|_{L^{2}(\Omega)}^{2} \leq\left\|h_{m, n}\right\|_{L^{2}(\Omega)}^{2}\left\|\operatorname{div} u_{m, n}\right\|_{L^{\infty}(\Omega)} .
$$

Owing to the Gronwall lemma, we obtain $\forall T>0, \forall t \in[0, T]$

$$
\left\|h_{m, n}(t)\right\|_{L^{2}(\Omega)}^{2} \leq\left\|h_{m, n}(0)\right\|_{L^{2}(\Omega)}^{2} \exp \left(\int_{0}^{t}\left\|\operatorname{div} u_{m, n}(\tau)\right\|_{L^{\infty}(\Omega)} \mathrm{d} \tau\right) .
$$

(ii) a priori estimates

When we obtain the energy estimate of the momentum equation, the terms $\left(u^{2}, \operatorname{div} u\right)$ and $(h, \operatorname{div} u)$ are not necessarily bounded.

First, we estimate these terms for a time $T_{n}$ which is sufficiently small, and then we show that $T_{n}$ does not go to 0 as $n$ goes to $+\infty$.

Next, we obtain a convergence result of $\left(u_{m, n}, h_{m, n}\right)$ to $\left(u_{m}, h_{m}\right)$ in $L^{1}(Q) \times$ $L^{1}(Q)$ weak as $n \rightarrow+\infty$. Finally, we prove that $\left(u_{m, n(m)}, h_{m, n(m)}\right)$ converges weakly to $(u, h)$ in $L^{1}(Q) \times L^{1}(Q)$, with a judicious choice of $n$.

Indeed, we have

$$
\int_{0}^{T} \int_{\Omega} h_{m, n} \operatorname{div} u_{m, n} \mathrm{~d} \Omega \mathrm{d} t \leq\left\|h_{m, n}\right\|_{L^{\infty}\left(0, T ; L^{2}(\Omega)\right)}\left\|\operatorname{div} u_{m, n}\right\|_{L^{1}\left(0, T ; L^{2}(\Omega)\right)}
$$

and thus

$$
\begin{gathered}
\int_{0}^{T} \int_{\Omega} h_{m, n} \operatorname{div} u_{m, n} \mathrm{~d} \Omega \mathrm{d} t \leq T\left\|h_{m, n}\right\|_{L^{\infty}\left(0, T ; L^{2}(\Omega)\right)}\left\|u_{m, n}\right\|_{L^{2}(0, T ; \mathcal{V})} \\
\leq c_{\varepsilon} T^{2}\left\|h_{m, n}\right\|_{L^{\infty}\left(0, T ; L^{2}(\Omega)^{2}\right)}^{2}+\varepsilon\left\|u_{m, n}\right\|_{L^{2}(0, T ; \mathcal{V})}^{2}
\end{gathered}
$$


The energy equation is given by

$$
\begin{array}{r}
\left(\frac{\partial u_{m, n}}{\partial t}, u_{m, n}\right)+A\left(\left(u_{m, n}, u_{m, n}\right)\right)-\frac{1}{2}\left(u_{m, n}^{2}, \operatorname{div} u_{m, n}\right) \\
-\left(h_{m, n}, \operatorname{div} u_{m, n}\right)=\left(f, u_{m, n}\right) .
\end{array}
$$

We estimate the right-hand side with

$$
\left(f, u_{m, n}\right) \leq \frac{1}{2 \lambda}\|f\|_{H^{-1}(\Omega)}^{2}+\frac{\lambda}{2}\left|u_{m, n}\right|_{\mathcal{V}}^{2} .
$$

Then, as $m$ is fixed, the integration in time gives

$$
\begin{aligned}
\frac{1}{2}\left\|u_{m, n}\right\|_{C^{0}\left(0, T ; L^{2}(\Omega)\right)}^{2} & -c_{2 \varepsilon} T^{2}\left\|h_{m, n}\right\|_{L^{\infty}\left(0, T ; L^{2}(\Omega)^{2}\right)}^{2} \\
+ & \left\|u_{m, n}\right\|_{L^{2}(0, T ; \mathcal{V})}^{2}\left[\left(A-\frac{\lambda}{2}-\varepsilon\right)-\frac{C}{2}\left\|u_{m, n}\right\|_{L^{\infty}\left(0, T ; L^{2}(\Omega)\right)}\right] \\
\leq & \frac{1}{2 \lambda}\|f\|_{L^{2}\left(0, T ; H^{-1}(\Omega)\right)}^{2}
\end{aligned}
$$

hence, with (4.65)

$$
\begin{gathered}
\frac{1}{2}\left\|u_{m, n}\right\|_{C^{0}\left(0, T ; L^{2}(\Omega)\right)}^{2}+\left\|u_{m, n}\right\|_{L^{2}(0, T ; \mathcal{V})}^{2}\left[\left(A-\frac{\lambda}{2}-\varepsilon\right)-\frac{C}{2}\left\|u_{m, n}\right\|_{L^{\infty}\left(0, T ; L^{2}(\Omega)\right)}\right] \\
-c_{\varepsilon} T^{2}\left\|h_{m, n}(0)\right\|_{L^{2}(\Omega)}^{2} \exp \left(\int_{0}^{T}\left\|\operatorname{div} u_{m, n}(t)\right\|_{L^{\infty}(\Omega)} \mathrm{d} t\right) \\
\leq \frac{1}{2 \lambda}\|f\|_{L^{2}\left(0, T ; H^{-1}(\Omega)\right)}^{2}
\end{gathered}
$$

Now, in order to obtain the a priori estimates, we must give an estimate for the expression

$$
c_{\varepsilon} T^{2}\left\|h_{m, n}(0)\right\|_{L^{2}(\Omega)}^{2} \exp \left(\int_{0}^{T}\left\|\operatorname{div} u_{m, n}(t)\right\|_{L^{\infty}(\Omega)} \mathrm{d} t\right) .
$$

We argue with a value of $T_{o, n}$ which is sufficiently small. $\forall \varepsilon_{1}>0$ and for each $n$ there exists $T_{o, n}>0$ such that, for each $t<T_{o, n}$, we obtain

$$
c_{\varepsilon} t^{2}\left\|h_{m, n}(0)\right\|_{L^{2}(\Omega)}^{2} \exp \left(\int_{0}^{t}\left\|\operatorname{div} u_{m, n}(\tau)\right\|_{L^{\infty}(\Omega)} \mathrm{d} \tau\right) \leq \varepsilon_{1}
$$

and thus

$$
\begin{gathered}
\frac{1}{4}\left\|u_{m, n}\right\|_{C^{0}\left(0, t ; L^{2}(\Omega)\right)}^{2}-c_{\varepsilon} t^{2}\left\|h_{m, n}(0)\right\|_{L^{2}(\Omega)}^{2} \exp \left(\int_{0}^{t}\left\|\operatorname{div} u_{m, n}(\tau)\right\|_{L^{\infty}(\Omega)} \mathrm{d} \tau\right) \\
\geq \frac{1}{4}\left\|u_{m, n}(0)\right\|_{L^{2}(\Omega)}^{2}-\varepsilon_{1}
\end{gathered}
$$


We must prove that $T_{o, n}$ does not go to zero as $n$ goes to infinity. $T_{0, n}$ is defined such that the following equation is satisfied:

$$
\begin{aligned}
& \frac{1}{4}\left\|u_{m, n}\right\|_{C^{0}\left(0, T_{o}, n ; L^{2}(\Omega)\right)}^{2} \\
& \quad-c_{\varepsilon} T_{o, n}^{2}\left\|h_{m, n}(0)\right\|_{L^{2}(\Omega)}^{2} \exp \left(\int_{0}^{T_{o, n}}\left\|\operatorname{div} u_{m, n}(\tau)\right\|_{L^{\infty}(\Omega)} \mathrm{d} \tau\right) \\
& =\frac{1}{4}\left\|u_{m, n}(0)\right\|_{L^{2}(\Omega)}^{2}-\varepsilon_{1}
\end{aligned}
$$

Let us suppose that $T_{0}>0$ does not exist such that (4.70) is satisfied for each $n$. This means that

$$
T_{o, n} \rightarrow 0 \text { as } n \rightarrow \infty
$$

and thus

$$
\left\|u_{m, n}\right\|_{C^{0}\left(0, T_{o}, n ; L^{2}(\Omega)\right)}^{2} \rightarrow\left\|u_{m, n}(0)\right\|_{L^{2}(\Omega)}^{2}-4 \varepsilon_{1} \text { as } n \rightarrow \infty
$$

which is impossible.

Consequently, we have the relation

$$
\begin{aligned}
& \frac{1}{4}\left\|u_{m, n}\right\|_{C^{0}\left(0, T ; L^{2}(\Omega)\right)}^{2} \\
& +\left\|u_{m, n}\right\|_{L^{2}(0, T ; \mathcal{V})}^{2}\left[\left(A-\frac{\lambda}{2}-\varepsilon\right)-\frac{C}{2}\left\|u_{m, n}\right\|_{L^{\infty}\left(0, T ; L^{2}(\Omega)\right)}\right] \\
& \leq \frac{1}{2 \lambda}\|f\|_{L^{2}\left(0, T ; H^{-1}(\Omega)^{2}\right)}^{2}-\frac{1}{4}\left\|u_{m, n}(0)\right\|_{L^{2}(\Omega)}^{2}+\varepsilon_{1}
\end{aligned}
$$

If we set $B=2 A-\lambda-2 \varepsilon$, we can obtain the a priori estimates if the data are chosen in order to satisfy the following equation

$$
B-C\left\|u_{m, n}\right\|_{L^{\infty}\left(0, T ; L^{2}(\Omega)\right)}>0
$$

Then, for each $t$, we must have

$$
\left\|u_{m, n}(t)\right\|_{L^{2}(\Omega)}<\frac{B}{C}
$$

and we argue as in $^{9}$.

We deduce that $u_{m, n}$ is bounded in $C^{0}\left(0, T_{0} ; L^{2}(\Omega)^{2}\right) \cap L^{2}\left(0, T_{0} ; \mathcal{V}\right), h_{m, n}$ is bounded in $L^{\infty}\left(0, T_{0} ; L^{2}(\Omega)\right)$ and we extract two sequences, noted $u_{m, n}$ and $h_{m, n}$ which converge to $u_{m}^{*}$ and $h_{m}^{*}$ as $n \rightarrow+\infty$ respectively.

The previous argument is true for $t \in\left[0, T_{o}\right.$. But the functions $u_{m, n}$ and $h_{m, n}$ are continuous in time and it is possible to extend these results on $[0, T[$ for each $T>0$. 
(iii) Passage to the limit

We are now going to prove that $u_{m, n} h_{m, n}$ converges weakly to $u_{m}^{*} h_{m}^{*}$ in $L^{2}\left(0, T ; L^{q}(\Omega)\right)$ (with $q<2$ ). To this end, we must verify that

$$
\begin{aligned}
\int_{\Omega}\left(u_{m, n} h_{m, n}-\right. & \left.u_{m}^{*} h_{m}^{*}\right) \varphi=\int_{\Omega} u_{m, n}\left(h_{m, n}-h_{m}^{*}\right) \varphi \\
& +\int_{\Omega} h_{m}^{*}\left(u_{m, n}-u_{m}^{*}\right) \varphi \quad \forall \varphi \in\left(L^{q}(\Omega)\right)^{\prime} .
\end{aligned}
$$

We have proven that $u_{m, n}$ is bounded in $L^{2}\left(0, T ; H^{1}(\Omega)^{2}\right)$ and then in $L^{2}\left(0, T ; L^{p}(\Omega)^{2}\right), p<\infty$, with embedding theorems. Moreover, we have $h_{m}^{*} \in$ $L^{2}\left(0, T ; L^{2}(\Omega)\right)$.

Thus, if we choose $\varphi$ in $L^{2}\left(0, T, L^{q}(\Omega)^{2}\right), q>2$, we obtain :

$$
h_{m}^{*} \varphi \in L^{2}\left(0, T ; L^{2-\varepsilon}(\Omega)\right) \text {. }
$$

Then

$$
\int_{\Omega}\left(u_{m, n}-u_{m}^{*}\right) h_{m}^{*} \varphi \rightarrow 0 \quad \text { as } n \rightarrow+\infty
$$

In the same way, we have $u_{m}^{*} \varphi \in L^{2}\left(0, T ; L^{2}(\Omega)^{2}\right)$, and, since $h_{m, n}$ converges weakly in $L^{2}(Q)$, then

$$
\int_{\Omega}\left(h_{m, n}-h_{m}^{*}\right) u_{m, n} \varphi \rightarrow 0 \text { as } n \rightarrow \infty .
$$

We deduce that $\left(u_{m}^{*}, h_{m}^{*}\right)$ is a solution of the problem $\left(V_{m}\right)$. As this problem has a unique solution ${ }^{2}$, we have $\left(u_{m}^{*}, h_{m}^{*}\right)=\left(u_{m}, h_{m}\right)$.

In the previous estimates, the convergence of $u_{m, n}$ (resp. $h_{m, n}$ ) to $u_{m}^{*}$ (resp. $h_{m}^{*}$ ) is not uniform in $m$. However, we show that we can extract a sequence from $\left(u_{m, n}, h_{m, n}\right)$, always denoted by $\left(u_{m n}, h_{m n}\right)$ which converges weakly in $\left(L^{2}\left(0, T ; L^{q}(\Omega)\right)\right)^{\prime}, q>2$. Indeed, we have:

$$
\int_{\Omega}\left(u_{m, n}-u\right) \varphi=\int_{\Omega}\left(u_{m, n}-u_{m}\right) \varphi+\int_{\Omega}\left(u_{m}-u\right) \varphi .
$$

The weak convergence of $u_{m}$ to $u$ gives

$$
\forall \varepsilon>0, \exists m / \int_{\Omega}\left(u_{m}-u\right) \varphi<\frac{\varepsilon}{2},
$$

and for each $m$, there exists $n(m)$ such that

$$
\int_{\Omega}\left(u_{m, n(m)}-u_{m}\right) \varphi<\frac{\varepsilon}{2}
$$

from which we obtain the result.

In the same way, we show the convergence of $h_{m, n}$ to $h$ and the convergence of $\left(u_{m, n} h_{m, n}\right)$ to $(u h)$. 


\subsection{Strong convergence results}

For a fixed value of $m$, we can establish some strong convergence results for $h_{m, n}$ with the Aubin theorem. Previously, we proved that $u_{m, n}$ is bounded into $C^{0}\left(0, T ; H^{4}(\Omega)^{2}\right)$. As $h_{m, n}$ is bounded into $L^{2}\left(0, T ; L^{2}(\Omega)\right)$, we have

$$
u_{m, n} h_{m, n} \text { bounded into } L^{2}\left(0, T ; L^{2}(\Omega)^{2}\right)
$$

hence

$$
\operatorname{div}\left(u_{m, n} h_{m, n}\right) \text { bounded into } L^{2}\left(0, T ; H^{-1}(\Omega)\right) .
$$

We thus deduce that $\frac{\partial h_{m, n}}{\partial t}$ is bounded into $L^{2}\left(0, T ; H^{-1}(\Omega)\right)$. The Aubin theorem with :

$h_{m, n}$ bounded into $L^{2}\left(0, T ; L^{2}(\Omega)\right)$ and $\frac{\partial h_{m, n}}{\partial t}$ bounded into $L^{2}\left(0, T ; H^{-1}(\Omega)\right)$, therefore gives

$$
h_{m, n} \longrightarrow h_{m} \quad \text { strongly in } L^{2}(Q) \text {. }
$$

In the same way, it is clear that $u_{m, n}$ converges strongly to $u_{m}$ in $L^{2}(Q)$.

It is possible to obtain an error estimate by substracting (2.18) from (4.60), multiplying by $h_{m, n}-h_{m}$ and integrating over $\Omega$. We obtain

$$
\begin{aligned}
\frac{1}{2} \frac{d}{d t}\left\|h_{m, n}-h_{m}\right\|_{L^{2}(\Omega)}^{2} & =\int_{\Omega} \operatorname{div}\left(u_{m} h_{m}\right)\left(h_{m, n}-h_{m}\right) \\
& -\int_{\Omega} \operatorname{div}\left[u_{m, n}\left(h_{m, n}-h_{m}\right)\right]\left(h_{m, n}-h_{m}\right) \\
& -\int_{\Omega} \operatorname{div}\left(u_{m, n} h_{m}\right)\left(h_{m, n}-h_{m}\right),
\end{aligned}
$$

therefore,

$$
\begin{aligned}
\frac{1}{2} \frac{d}{d t}\left\|h_{m, n}-h_{m}\right\|_{L^{2}(\Omega)}^{2} & \leq\left\|h_{m, n}-h_{m}\right\|_{L^{2}(\Omega)}\left(\left\|\operatorname{div}\left(u_{m} h_{m}\right)\right\|_{L^{2}(\Omega)}\right. \\
+ & \left.\left\|\operatorname{div}\left(u_{m, n} h_{m}\right)\right\|_{L^{2}(\Omega)}\right) \\
& -\int_{\Omega} \operatorname{div}\left[u_{m, n}\left(h_{m, n}-h_{m}\right)\right]\left(h_{m, n}-h_{m}\right) .
\end{aligned}
$$

The last term on the right-hand side of (4.74) is changed to

$$
\int_{\Omega} \operatorname{div}\left[u_{m, n}\left(h_{m, n}-h_{m}\right)\right]\left(h_{m, n}-h_{m}\right)=\frac{1}{2} \int_{\Omega} \operatorname{div}\left(u_{m, n}\right)\left(h_{m, n}-h_{m}\right)^{2} .
$$

Integrating (4.74) in time, it comes

$$
\begin{aligned}
& \sup _{t}\left\|h_{m, n}(t)-h_{m}(t)\right\|_{L^{2}(\Omega)}^{2} \leq 2\left\|h_{m, n}-h_{m}\right\|_{L^{2}(Q)}\left(\left\|\operatorname{div}\left(u_{m} h_{m}\right)\right\|_{L^{2}(Q)}\right. \\
& \left.+\left\|\operatorname{div}\left(u_{m, n} h_{m}\right)\right\|_{L^{2}(Q)}\right)+\left\|h_{m, n}(0)-h_{m}(0)\right\|_{L^{2}(\Omega)}^{2} \\
& -\int_{Q} \operatorname{div}\left(u_{m, n}\right)\left(h_{m, n}-h_{m}\right)^{2} \text {. }
\end{aligned}
$$


Finally, as $h_{m, n}$ converges strongly to $h_{m}$ in $L^{2}(Q)$,

$$
\exists N \in N / \forall n>N, \quad\left(h_{m, n}-h_{m}\right)^{2} \leq\left(h_{m, n}-h_{m}\right)<1 .
$$

Thus,

$$
\begin{aligned}
\sup _{t}\left\|h_{m, n}(t)-h_{m}(t)\right\|_{L^{2}(\Omega)}^{2} \leq\left\|h_{m, n}-h_{m}\right\|_{L^{2}(Q)}\left(2\left\|\operatorname{div}\left(u_{m} h_{m}\right)\right\|_{L^{2}(Q)}\right. \\
\left.+2\left\|\operatorname{div}\left(u_{m, n} h_{m}\right)\right\|_{L^{2}(Q)}+\left\|\operatorname{div}\left(u_{m, n}\right)\right\|_{L^{2}(Q)}\right) \\
+\left\|h_{m, n}(0)-h_{m}(0)\right\|_{L^{2}(\Omega)}^{2}
\end{aligned}
$$

We can obtain some stronger convergence results if we argue as $\mathrm{in}^{2}$.

\subsection{Numerical resolution method}

Theorem 2.2 proves that the set composed of the functions $p_{k}$ which are solutions to problem $(P 2)$, constitute an orthogonal basis of $H^{1}(\Omega)$. This basis is used for the projection of the continuity equation. We thus obtain $m+n$ equations of the form

$$
\begin{aligned}
\frac{d x_{i}}{d t} & =F_{i}\left(x_{j}, x_{k}\right)+H_{i}\left(y_{j}\right) \\
\frac{d y_{i}}{d t} & =\Theta_{i}\left(x_{j}, y_{k}\right)
\end{aligned}
$$

The functions $F_{i}, H_{i}$ and $\Theta_{i}$ are obtained by integration on the domain of basis functions. Contrary to the methods using the characteristics, it is not necessary to compute the trajectory and to evaluate integrals on the domain for each time step. However, the presence of several non linear terms are costly in terms of CPU time.

\section{Global nonlinear Galerkin method}

In the previous section, we justified the use of the Galerkin method to solve the continuity equation. We will now apply the nonlinear Galerkin method to the momentum and continuity equations. This method allows us to reduce the simulation time.

\subsection{Description of the method}

We define $u_{m, n}=y_{m, n}+z_{m, n}$ with

$$
y_{m, n}=\sum_{i=1}^{m_{1}} x_{i}(t) \varphi(x) \text { and } z_{m, n}=\sum_{i=m_{1}+1}^{m} x_{i}(t) \varphi(x)
$$

and $h_{m, n}=\zeta_{m, n}+\eta_{m, n}$ with

$$
\zeta_{m, n}=\sum_{k=1}^{n_{1}} y_{k}(t) p_{k}(x) \text { and } \eta_{m, n}=\sum_{k=n_{1}+1}^{n} y_{k}(t) p_{k}(x)
$$


solutions of the following problem $\left(V_{m, n}^{a}\right)$

$$
\begin{gathered}
\left(\frac{\partial y_{m, n}}{\partial t}, \varphi_{i}\right)+b\left(y_{m, n}, y_{m, n}, \varphi_{i}\right)+b\left(y_{m, n}, z_{m, n}, \varphi_{i}\right)+b\left(z_{m, n}, y_{m, n}, \varphi_{i}\right) \\
+\left(\alpha\left(y_{m, n}\right), \varphi_{i}\right)+\left(\alpha\left(z_{m, n}\right), \varphi_{i}\right)+A\left(\left(y_{m, n}, \varphi_{i}\right)\right) \\
-\left(\zeta_{m, n}, \operatorname{div} \varphi_{i}\right)-\left(\eta_{m, n}, \operatorname{div} \varphi_{i}\right)=\left(f, \varphi_{i}\right), \forall \varphi_{i}, i=1, \ldots, m_{1} \\
\left(\frac{\partial \zeta_{m, n}}{\partial t}, p_{k}\right)-\left(y_{m, n} \zeta_{m, n}, \operatorname{grad} p_{k}\right)-\left(y_{m, n} \eta_{m, n}, \operatorname{grad} p_{k}\right) \\
-\left(z_{m, n} \zeta_{m, n}, \operatorname{grad} p_{k}\right)=0, \forall p_{k}, k=1, \ldots, n_{1} \\
\left(\frac{\partial z_{m}}{\partial t}, \varphi_{i}\right)+b\left(y_{m, n}, y_{m, n}, \varphi_{i}\right)+\left(\alpha\left(y_{m, n}\right), \varphi_{i}\right)+A\left(\left(z_{m, n}, \varphi_{i}\right)\right) \\
-\left(\zeta_{m, n}, \operatorname{div} \varphi_{i}\right)=\left(f, \varphi_{i}\right), \varphi_{i}, \forall i=m_{1}+1, \ldots, m \\
\left(\frac{\partial \eta_{m, n}}{\partial t}, p_{k}\right)-\left(y_{m, n} \zeta_{m, n}, \operatorname{grad} p_{k}\right)=0, \forall p_{k}, k=n_{1}+1, \ldots, n
\end{gathered}
$$

where $b(,$,$) represents the nonlinear terms.$

\subsection{Weak convergence results}

If $\varepsilon$ and $\varepsilon^{\prime}$ are two positive constants, then we obtain the following result

Theorem 5.5 All the constants are defined as in Theorem 2.1, except for B, which is defined by $B=\left(A-\frac{\lambda}{2}-\max \left(\varepsilon, \varepsilon^{\prime}\right)\right) / \sqrt{2}$.

Let $u_{0} \in \mathcal{V}, h_{0} \in L^{2}$ and $f \in L^{2}\left(0, T, H^{-1}(\Omega)^{2}\right)$ satisfying

$$
\begin{gathered}
\frac{2}{\lambda}\|f\|_{L^{2}\left(0, T ; H^{-1}(\Omega)\right)}^{2}+\left\|y_{0 m}+z_{0 m}\right\|_{L^{2}(\Omega)}^{2}+4 \varepsilon_{1} \leq \theta\left(\frac{B}{C}\right)^{2} \\
\|u(0)\|_{L^{2}(\Omega)} \leq \theta\left(\frac{B}{C}\right)
\end{gathered}
$$

Then

- $z_{m, n} \rightarrow 0$ weakly in $L^{2}(0, T ; \mathcal{V})$.

- $z_{m, n} \rightarrow 0$ strongly in $L^{2}\left(0, T ; L^{2}(\Omega)^{2}\right)$.

- $y_{m, n} \rightarrow 0$ weakly in $L^{2}(0, T ; \mathcal{V})$ and weakly in $L^{\infty}\left(0, T ; L^{2}(\Omega)^{2}\right)$-* $^{*}$.

- $\forall \delta>0, \forall m, \exists N(m) /$

$\forall n>N(m), \int_{Q} \zeta_{m, n} \Theta d x d t-\int_{Q} h \Theta d x d t<\delta \quad \forall \Theta \in L^{1}\left(0, T ; L^{\infty}(\Omega)\right)$.

- $\frac{\partial y_{m, n}}{\partial t}$ bounded in $L^{2}\left(0, T ; H^{-3}(\Omega)^{2}\right)$

- $\left(\operatorname{curl} y_{m, n} \alpha\left(z_{m, n}\right), \varphi\right)_{L^{2}(\Omega)^{2}} \rightarrow 0$ strongly in $L^{1}(0, T)$.

- $\left(\operatorname{curl} z_{m, n} \alpha\left(y_{m, n}\right), \varphi\right)_{L^{2}(\Omega)^{2}} \rightarrow 0$ strongly in $L^{1}(0, T)$. 
- $\left(y_{m, n} z_{m, n}, \operatorname{div} \varphi\right)_{L^{2}(\Omega)^{2}} \rightarrow 0$ strongly in $L^{1}(0, T)$.

- $\left(y_{m, n} \eta_{m, n}, \nabla p_{i}\right)_{L^{2}(\Omega)^{2}} \rightarrow 0$ strongly in $L^{1}(0, T)$.

- $\left(y_{m, n}, \zeta_{m, n}\right)$ converges weakly to $\left(u_{m}, h_{m}\right)$ in $L^{2}\left(0, T ; L^{q}(\Omega)\right)$ for $q<2$ where $\left(u_{m}, h_{m}\right)$ is the solution of $\left(V_{m}\right)$.

- $\forall m>0$, there exists $n(m)$ such as $\left(y_{m, n(m)}, \zeta_{m, n(m)}\right)$ converges weakly to $(u, h)$ solution of $(V)$ in $L^{1}(Q) \times L^{1}(Q)$.

The three main steps of the theorem proof are the following:

- Estimate of $\zeta_{m, n}$ and $\eta_{m, n}$ according to $y_{m, n}$ and $z_{m, n}$.

- a priori estimate for $y_{m, n}$ and $z_{m, n}$.

- Passage to the limit.

\section{Proof.}

(i) Estimate of $\zeta_{m, n}$ and $\eta_{m, n}$ according to $y_{m, n}$ and $z_{m, n}$

First, we estimate $\left\|\zeta_{m, n}\right\|_{L^{2}(\Omega)}+\left\|\eta_{m, n}\right\|_{L^{2}(\Omega)}$ according to $\left\|u_{m, n}\right\|_{L^{\infty}\left(0, T ; L^{2}(\Omega)^{2}\right)}^{2}$. In order to obtain this estimate, we set $p_{k}=\zeta_{m, n}$ in (5.81) and $p_{k}=\eta_{m, n}$ in (5.83) and we add the two equations

$$
\begin{aligned}
\frac{1}{2} \frac{\mathrm{d}}{\mathrm{d} t}[ & {\left[\left\|\zeta_{m, n}\right\|_{L^{2}(\Omega)}^{2}+\left\|\eta_{m, n}\right\|_{L^{2}(\Omega)}^{2}\right]-\left(y_{m, n} \zeta_{m, n}, \nabla \zeta_{m, n}\right) } \\
& -\left(y_{m, n} \zeta_{m, n}, \nabla \eta_{m, n}\right)-\left(z_{m, n} \zeta_{m, n}, \nabla \zeta_{m, n}\right) \\
& -\left(y_{m, n} \eta_{m, n}, \nabla \zeta_{m, n}\right)=0 .
\end{aligned}
$$

Since we have

$$
\begin{aligned}
\left(y_{m, n} \zeta_{m, n}, \nabla \zeta_{m, n}\right) & =-\frac{1}{2}\left(\zeta_{m, n}^{2}, \operatorname{div} y_{m, n}\right), \\
\left(z_{m, n} \zeta_{m, n}, \nabla \zeta_{m, n}\right) & =-\frac{1}{2}\left(\zeta_{m, n}^{2}, \operatorname{div} z_{m, n}\right)
\end{aligned}
$$

and

$$
\left(y_{m, n} \zeta_{m, n}, \nabla \eta_{m, n}\right)=-\left(y_{m, n} \eta_{m, n}, \nabla \zeta_{m, n}\right)-\left(\zeta_{m, n} \eta_{m, n}, \operatorname{div} y_{m, n}\right),
$$

we obtain

$$
\begin{aligned}
\frac{1}{2} \frac{\mathrm{d}}{\mathrm{d} t}\left[\left\|\zeta_{m, n}\right\|_{L^{2}(\Omega)}^{2}\right. & \left.+\left\|\eta_{m, n}\right\|_{L^{2}(\Omega)}^{2}\right]+\frac{1}{2}\left(\zeta_{m, n}^{2}, \operatorname{div} y_{m, n}\right) \\
& +\frac{1}{2}\left(\zeta_{m, n}^{2}, \operatorname{div} z_{m, n}\right)+\left(\zeta_{m, n} \eta_{m, n}, \operatorname{div} y_{m, n}\right)=0
\end{aligned}
$$

We can write the following estimate

$$
\begin{aligned}
\frac{\mathrm{d}}{\mathrm{d} t}\left[\left\|\eta_{m, n}\right\|_{L^{2}(\Omega)}^{2}+\right. & \left.\left\|\zeta_{m, n}\right\|_{L^{2}(\Omega)}^{2}\right] \leq\left[\left\|\eta_{m, n}\right\|_{L^{2}(\Omega)}^{2}+\left\|\zeta_{m, n}\right\|_{L^{2}(\Omega)}^{2}\right] \\
\cdot & {\left[\left\|\operatorname{div} y_{m, n}\right\|_{L^{\infty}(\Omega)}+\left\|\operatorname{div} z_{m, n}\right\|_{L^{\infty}(\Omega)}\right] . }
\end{aligned}
$$


Using the Gronwall lemma, we obtain $\forall T>0$,

$$
\begin{aligned}
&\left\|\eta_{m, n}\right\|_{L^{2}(\Omega)}^{2}+\left\|\zeta_{m, n}\right\|_{L^{2}(\Omega)}^{2} \leq\left(\left\|\eta_{m, n}(0)\right\|_{L^{2}(\Omega)}^{2}+\left\|\zeta_{m, n}(0)\right\|_{L^{2}(\Omega)}^{2}\right) \\
& \exp \left(\int_{0}^{T}\left[\left\|\operatorname{div} y_{m, n}\right\|_{L^{\infty}(\Omega)}+\left\|\operatorname{div} z_{m, n}\right\|_{L^{\infty}(\Omega)}\right] \mathrm{d} t\right)
\end{aligned}
$$

(ii) a priori estimate of $y_{m, n}$ and $z_{m, n}$

The energy equation is obtained by setting $\varphi_{i}=y_{m, n}$ in (5.80) and $\varphi_{i}=$ $z_{m, n}$ in (5.82). Then, by adding the two equations, we obtain

$$
\begin{aligned}
\frac{1}{2}\left(\frac{\mathrm{d}}{\mathrm{d} t}\left\|y_{m, n}\right\|_{L^{2}(\Omega)}^{2}\right. & \left.+\frac{\mathrm{d}}{\mathrm{d} t}\left\|z_{m, n}\right\|_{L^{2}(\Omega)}^{2}\right)+A\left(\left|y_{m, n}\right|_{\mathcal{V}}^{2}+\left|z_{m, n}\right|_{\mathcal{V}}^{2}\right) \\
& -\left(\zeta_{m, n}, \operatorname{div} y_{m, n}\right)-\left(\eta_{m, n}, \operatorname{div} y_{m, n}\right) \\
& -\left(\zeta_{m, n}, \operatorname{div} z_{m, n}\right)-\frac{1}{2}\left(y_{m, n}^{2}, \operatorname{div} y_{m, n}\right) \\
& -\left(y_{m, n} z_{m, n}, \operatorname{div} y_{m, n}\right)-\frac{1}{2}\left(y_{m, n}^{2}, \operatorname{div} z_{m, n}\right) \\
& =\left(f, y_{m, n}\right)+\left(f, z_{m, n}\right) .
\end{aligned}
$$

The nonlinear terms and the terms with $\eta_{m, n}$ and $\zeta_{m, n}$ are not necessarily bounded. In order to solve this difficulty, we argue as in Theorem 3.3. First, we write

$$
\begin{array}{rl}
\int_{0}^{T} \int_{\Omega} \eta_{m, n} \operatorname{div} y_{m, n} & \mathrm{~d} \Omega \mathrm{d} t+\int_{0}^{T} \int_{\Omega} \zeta_{m, n} \operatorname{div} z_{m, n} \mathrm{~d} \Omega \mathrm{d} t \\
\leq & \left\|\eta_{m, n}\right\|_{L^{\infty}\left(0, T ; L^{2}(\Omega)\right)}\left\|\operatorname{div} y_{m, n}\right\|_{L^{1}\left(0, T ; L^{2}(\Omega)\right)} \\
& +\left\|\zeta_{m, n}\right\|_{L^{\infty}\left(0, T ; L^{2}(\Omega)\right)}\left\|\operatorname{div} z_{m, n}\right\|_{L^{1}\left(0, T ; L^{2}(\Omega)\right)}
\end{array}
$$

and

$$
\begin{array}{rl}
\int_{0}^{T} \int_{\Omega} \eta_{m, n} \operatorname{div} y_{m, n} & \mathrm{~d} \Omega \mathrm{d} t+\int_{0}^{T} \int_{\Omega} \zeta_{m, n} \operatorname{div} z_{m, n} \mathrm{~d} \Omega \mathrm{d} t \\
\leq & T\left\|\eta_{m, n}\right\|_{L^{\infty}\left(0, T ; L^{2}(\Omega)\right)}\left\|y_{m, n}\right\|_{L^{2}(0, T ; \mathcal{V})} \\
& +T\left\|\zeta_{m, n}\right\|_{L^{\infty}\left(0, T ; L^{2}(\Omega)\right)}\left\|z_{m, n}\right\|_{L^{2}(0, T ; \mathcal{V})} .
\end{array}
$$

Therefore, with $\varepsilon$ and $\varepsilon^{\prime}$ arbitrarily chosen, we obtain

$$
\begin{array}{rl}
\int_{0}^{T} \int_{\Omega} \eta_{m, n} \operatorname{div} y_{m, n} & \mathrm{~d} \Omega \mathrm{d} t+\int_{0}^{T} \int_{\Omega} \zeta_{m, n} \operatorname{div} z_{m, n} \mathrm{~d} \Omega \mathrm{d} t \\
\leq & c_{\varepsilon} T^{2}\left(\left\|\eta_{m, n}\right\|_{L^{\infty}\left(0, T ; L^{2}(\Omega)^{2}\right)}^{2}+\left\|\zeta_{m, n}\right\|_{L^{\infty}\left(0, T ; L^{2}(\Omega)^{2}\right)}^{2}\right) \\
& +\varepsilon\left\|y_{m, n}\right\|_{L^{2}(0, T ; \mathcal{V})}^{2}+\varepsilon^{\prime}\left\|z_{m, n}\right\|_{L^{2}(0, T ; \mathcal{V})}^{2} \\
\leq & c_{\varepsilon} T^{2}\left(\left\|\eta_{m, n}\right\|_{L_{\left(0, T ; L^{2}(\Omega)^{2}\right)}^{2}}^{2}+\left\|\zeta_{m, n}\right\|_{L^{\infty}\left(0, T ; L^{2}(\Omega)^{2}\right)}^{2}\right) \\
& +\max \left(\varepsilon, \varepsilon^{\prime}\right)\left\|u_{m, n}\right\|_{L^{2}(0, T ; \mathcal{V})}^{2} .
\end{array}
$$


Next, we bound the right-hand side as follows

$$
\left(f, y_{m, n}\right)+\left(f, z_{m, n}\right) \leq \frac{1}{2 \lambda}\|f\|_{H^{-1}(\Omega)}^{2}+\frac{\lambda}{2}\left|u_{m, n}\right|_{\mathcal{V}}^{2}
$$

the nonlinear terms are bounded as in section 3

$\frac{1}{2}\left(y_{m, n}^{2}, \operatorname{div} u_{m, n}\right)+\left(y_{m, n} z_{m, n}, \operatorname{div} y_{m, n}\right) \leq \sqrt{2} C\left\|u_{m, n}\right\|_{L^{2}(\Omega)}\left|u_{m, n}\right|_{\mathcal{V}}^{2}$.

By integrating the energy equation over time, we obtain the following estimate

$$
\begin{aligned}
& \frac{1}{2}\left(\left\|y_{m, n}\right\|_{C^{0}\left(0, T ; L^{2}(\Omega)\right)}^{2}+\left\|z_{m, n}\right\|_{C^{0}\left(0, T ; L^{2}(\Omega)\right)}^{2}\right) \\
& \quad+\left\|u_{m, n}\right\|_{L^{2}(0, T ; \mathcal{V})}^{2}\left[\left(A-\frac{\lambda}{2}-\max \left(\varepsilon, \varepsilon^{\prime}\right)\right)-\sqrt{2} C\left\|u_{m, n}\right\|_{L^{\infty}\left(0, T ; L^{2}(\Omega)\right)}\right] \\
& \quad-c_{\varepsilon} T^{2}\left(\left\|\eta_{m, n}\right\|_{L^{\infty}\left(0, T ; L^{2}(\Omega)^{2}\right)}^{2}+\left\|\zeta_{m, n}\right\|_{L^{\infty}\left(0, T ; L^{2}(\Omega)^{2}\right)}^{2}\right) \\
& \quad \leq \frac{2}{\lambda}\|f\|_{L^{2}\left(0, T ; H^{-1}(\Omega)\right)}^{2}
\end{aligned}
$$

We must estimate the term

$$
T^{2} \exp \left(\int_{0}^{T}\left(\left\|\operatorname{div} y_{m, n}(t)\right\|_{L^{\infty}(\Omega)}+\left\|\operatorname{div} z_{m, n}(t)\right\|_{L^{\infty}(\Omega)}\right) \mathrm{d} t\right)
$$

Then, we argue as in section 4 with a small time step $T_{o, n}$. If $n$ is given and $\forall \varepsilon_{1}>0$, then there exists $T_{o, n}>0$ such that, for each $t, t \leq T_{o, n}$, we have

$$
\begin{aligned}
\frac{1}{4}\left\|u_{m, n}(t)\right\|_{C^{0}\left(0, t ; L^{2}(\Omega)^{2}\right)}^{2}-c_{\varepsilon} t^{2}\left(\left\|\eta_{m, n}(0)\right\|_{L^{2}(\Omega)}^{2}+\left\|\zeta_{m, n}(0)\right\|_{L^{2}(\Omega)}^{2}\right) \\
\quad . \exp \left(\int_{0}^{t}\left(\left\|\operatorname{div} y_{m, n}(\tau)\right\|_{L^{\infty}(\Omega)}+\left\|\operatorname{div} z_{m, n}(\tau)\right\|_{L^{\infty}(\Omega)}\right) \mathrm{d} \tau\right) \\
\geq \frac{1}{4}\left\|u_{m, n}(0)\right\|_{L^{2}(\Omega)}^{2}-\varepsilon_{1} .
\end{aligned}
$$

We need to verify that $T_{o, n}$ does not go to zero as $n$ goes to infinity. $T_{0, n}$ is defined such that the following equation is satisfied:

$$
\begin{aligned}
& \frac{1}{4}\left\|u_{m, n}\right\|_{C^{0}\left(0, T_{o, n} ; L^{2}(\Omega)\right)}^{2}-c_{\varepsilon}^{2} T_{0, n}^{2}\left(\left\|\eta_{m, n}(0)\right\|_{L^{2}(\Omega)}^{2}+\left\|\zeta_{m, n}(0)\right\|_{L^{2}(\Omega)}^{2}\right) . \\
& . \exp \left(\int_{0}^{T_{0, n}}\left(\left\|\operatorname{div} y_{m, n}(\tau)\right\|_{L^{\infty}(\Omega)}+\left\|\operatorname{div} z_{m, n}(\tau)\right\|_{L^{\infty}(\Omega)}\right) \mathrm{d} \tau\right) \\
& =\frac{1}{4}\left\|u_{m, n}(0)\right\|_{L^{2}(\Omega)}^{2}-\varepsilon_{1} .
\end{aligned}
$$

We now suppose that $T_{o, n}$ does not exist such that (5.97) is satisfied for each value of $n$. This means that

$$
T_{o, n} \rightarrow 0 \text { as } n \rightarrow \infty
$$


and then

$$
\left\|u_{m, n}\right\|_{C^{0}\left(0, T_{o}, n ; L^{2}(\Omega)\right)}^{2} \rightarrow\left\|u_{m, n}(0)\right\|_{L^{2}(\Omega)}^{2}-4 \varepsilon_{1} \text { as } n \rightarrow \infty,
$$

which is impossible.

We thus obtain the inequality:

$$
\begin{aligned}
& \frac{1}{4} \frac{\mathrm{d}}{\mathrm{d} t}\left\|u_{m, n}\right\|_{L^{2}(\Omega)}^{2}+\left|u_{m, n}\right|_{\mathcal{V}}^{2}\left[\left(A-\frac{\lambda}{2}-\max \left(\varepsilon, \varepsilon^{\prime}\right)\right)-\frac{C}{2}\left\|y_{m, n}\right\|_{L^{2}(\Omega)}\right] \\
& \leq \frac{1}{2 \lambda}\|f\|_{H^{-1}(\Omega)}^{2}-\frac{1}{4}\left|u_{m, n}(0)\right|_{\mathcal{V}}^{2}+\varepsilon_{1}
\end{aligned}
$$

If we set $B=\left(A-\frac{\lambda}{2}-\max \left(\varepsilon, \varepsilon^{\prime}\right)\right) / \sqrt{2}$, then the estimates are obtained by choosing the data such that :

$$
B-C\left\|u_{m, n}\right\|_{L^{2}(\Omega)}>0 .
$$

For each value of $t$, we must have :

$$
\left\|u_{m, n}\right\|_{L^{2}(\Omega)}<\frac{B}{C}
$$

To prove this point, we argue as in ${ }^{9}$.

We deduce that $y_{m, n}$ and $z_{m, n}$ are bounded in $C^{0}\left(0, T_{0} ; L^{2}(\Omega)^{2}\right) \cap L^{2}\left(0, T_{0} ; \mathcal{V}\right)$ and that we extract two sequences, still denoted by $y_{m, n}$ and $z_{m, n}$, which converge weakly to $y_{m}^{*}$ and $z_{m}^{*}$ as $n \rightarrow+\infty$.

In the same way $\zeta_{m, n}$ and $\eta_{m, n}$ are bounded in $L^{\infty}\left(0, T_{0}, L^{2}(\Omega)\right)$ and we can extract two sequences, still denoted by $\zeta_{m, n}$ and $\eta_{m, n}$, which converge weakly-* to $\zeta_{m}^{*}$ and $\eta_{m}^{*}$.

The previous argument is true for $t \in\left[0, T_{0}[\right.$. As all the functions are continuous, it is possible to extend the result on $[0, T[, \forall T>0$.

(iii) Passage to the limit

Owing to the definition of $\eta_{m, n}$, it is evident that :

$$
\forall p_{k}, \quad \int_{\Omega} \eta_{m, n} p_{k}=0 \quad \text { when } n_{1}>k,
$$

and $\eta_{m, n} \rightarrow 0$ weakly in $L^{\infty}(Q)$, as $n \rightarrow+\infty$.

It therefore follow that

$$
\int_{Q} \eta_{m, n} y_{m, n} \operatorname{grad} p_{k} \rightarrow 0 \text { as } n \rightarrow \infty \text {. }
$$

Next, as $z_{m, n}$ is bounded in $L^{2}(0, T ; \mathcal{V})$, we can prove, using an argument similar to that of section 3.1 , that:

$$
z_{m, n} \rightarrow 0 \text { strongly in } L^{2}(Q) \text { as } n \rightarrow+\infty \text {. }
$$


Finally, with the properties of the basis, we have

$$
\left(\eta_{m, n}, \operatorname{div} \varphi_{k}\right)=-\lambda_{k}^{\frac{1}{2}}\left(\eta_{m, n}, p_{k}\right) \rightarrow 0 \text { as } n \rightarrow+\infty .
$$

By using the same argument as in the global Galerkin method, we can prove that:

$$
\int_{\Omega}\left(y_{m, n} \zeta_{m, n}-y_{m}^{*} \zeta_{m}^{*}\right) \varphi \rightarrow 0 \text { as } n \rightarrow+\infty .
$$

We deduce that $\left(y_{m}^{*}, \zeta_{m}^{*}\right)$ is a solution to problem $\left(V_{m}\right)$. Since this solution is unique, we necessarily have $\left(y_{m}^{*}, \zeta_{m, n}^{*}\right)=\left(u_{m}, h_{m}\right)$.

The convergence of $y_{m, n}\left(\operatorname{resp} . \zeta_{m, n}\right)$ to $u_{m}$ (resp. $h_{m}$ ) is not uniform with $m$ and we can not directly conclude that $y_{m, n}$ (resp. $\zeta_{m, n}$ ) converges to $u$ (resp. h). As in the case of the global Galerkin method, However, with a judicious choice of $m$ and $n$, we can obtain the difference between $y_{m, n}$ and $u$ (resp. $\zeta_{m, n}$ and $h$ ) which is as small as we wish.

\subsection{Strong convergence results}

As in section 4.3, we can establish some strong convergence results for $\zeta_{m, n}$ with the Aubin theorem, for a fixed value of $m$. First we deduce that

$$
\zeta_{m, n} \longrightarrow h_{m} \text { strongly in } L^{2}(Q)
$$

with the Aubin theorem.

In the same way, we prove that $y_{m, n}$ converges strongly to $u_{m}$ in $L^{2}(Q)$.

It is possible to obtain an error estimate by substracting (2.18) from (5.81), multiplying by $\zeta_{m, n}-h_{m}$ and integrating over $\Omega$. We obtain

$$
\begin{aligned}
\frac{1}{2} \frac{d}{d t}\left\|\zeta_{m, n}-h_{m}\right\|_{L^{2}(\Omega)}^{2} & =\int_{\Omega} \operatorname{div}\left(u_{m} h_{m}\right)\left(\zeta_{m, n}-h_{m}\right) \\
& -\int_{\Omega} \operatorname{div}\left(u_{m, n} \zeta_{m, n}\right)\left(\zeta_{m, n}-h_{m}\right) \\
& -\int_{\Omega} \operatorname{div}\left(y_{m, n} \eta_{m, n}\right)\left(\zeta_{m, n}-h_{m}\right),
\end{aligned}
$$

and finally, as in section 4.3 ,

$$
\begin{aligned}
\sup _{t} \| \zeta_{m, n}(t) & -h_{m}(t)\left\|_{L^{2}(\Omega)}^{2} \leq\right\| \zeta_{m, n}-h_{m} \|_{L^{2}(Q)}\left(2\left\|\operatorname{div}\left(u_{m} h_{m}\right)\right\|_{L^{2}(Q)}\right. \\
& +2\left\|\operatorname{div}\left(u_{m, n} h_{m}\right)\right\|_{L^{2}(Q)}+\left\|\operatorname{div}\left(u_{m, n}\right)\right\|_{L^{2}(Q)} \\
& \left.+2\left\|\operatorname{div}\left(y_{m, n} \eta_{m, n}\right)\right\|_{L^{2}(Q)}\right)+\left\|h_{m, n}(0)-h_{m}(0)\right\|_{L^{2}(\Omega)}^{2}
\end{aligned}
$$

\section{Numerical applications}

\subsection{Computation}


In order to compare the results presented here with previous results, we make the following assumptions :

The studied domain is a square with 1000 kilometers in length. If we change the spatial and temporal scales, this square is transformed into a square of one unit in length.

We consider a fluid layer of density $\rho_{2}$ and mean elevation of 200 meters, which moves on a fixed fluid layer of density $\rho_{1}\left(>\rho_{2}\right)$. We replace the acceleration of the gravity with a coefficient of reduced gravity $g^{\prime}$ defined by

$$
g^{\prime}=\frac{\rho_{1}-\rho_{2}}{\rho_{1}} g
$$

here, $g^{\prime}=2 \cdot 10^{-2} \mathrm{~m} \cdot \mathrm{s}^{-2}$.

The boundary conditions express waterproof conditions on all the boundaries. The surface stress is the wind stress tensor used by P. Orenga ${ }^{1}$ and F.J. Chatelon ${ }^{2}$.

The space discretization used for the integrations and the method of the characteristics is 1860 elements uniformly distributed over the domain. The real time step is approximatively 15 minutes. The coefficient of eddy viscosity is $10^{-1} \mathrm{~m}^{2} \cdot \mathrm{s}^{-1}$. This coefficient is chosen sufficiently small in order to obtain a significant representation of the fluid circulation on the first 60 eigen functions for velocity.

\subsection{Remarks}

With the method of the characteristics, we evaluate the water elevation on the mesh points. We have to interpolate the value on each element and to make numerical integrations on these elements. The cost of this method is proportional to the number of elements.

On the other hand, when we use the Galerkin method, the space discretization is only made for the computation of the constant coefficients (once for a given domain) and the representation of results. The computation costs are (nearly) independent of the mesh, but they directly depend on the dimension of the space to which the solution belongs.

Thus, comparison of the different methods is problematic, to which we add the optimization of algorithm and the use of different stability criteria for each numerical scheme. Although we have sought, where possible, to optimize codes and parameters, the results may not be optimum.

The advantages of the global nonlinear Galerkin method as compared to the global Galerkin method are presented $\mathrm{in}^{4}$. In particular, a comparison was made in the present study, between the method of the characteristics and the Galerkin method in solving the continuity equation.

\subsection{Numerical scheme}


The particular geometry of the domain allows us to obtain an analytical solution to problems $(P 2)$ and $(P 3)$. In a general case, these problems are solved with ModulEf, the finite elements software developped by the INRIA. If we use Hermite's finite element with three degrees of freedom, we directly obtain the gradient and the Curl of the functions without numerical differenciation.

We have chosen a method of quadrature in order to accurately integrate the diffusion term ${ }^{4}$. This method allows us to use a greater time step than in the classical methods and it is particularly adapted to high frequencies. The other terms are integrated with an implicit Euler scheme.

\subsection{Results and discussion}

Theoretically, the method of the characteristics for the continuity equation gives the best approximation of the solution. Then, we use as reference value, the results obtained using the usual Galerkin method for the momentum equation and the method of the characteristics for the continuity equation.

(i) Comparison between the usual Galerkin method and the method of the characteristics

First, we compare the results obtained using the method of the characteristics and the Galerkin method according to the number of eigen functions. We use the notion of potential energy $(E p)$; this notion corresponds to the energy stored by the deformation of the fluid layer ${ }^{6}$ :

$$
E p=\frac{1}{2} \rho g(h-\bar{h})^{2}
$$

where $\bar{h}$ represents the reference state and $\rho$ the density of the fluid which is supposed to be constant. During the decomposition of the variations in water elevation by the Galerkin method, the potential energy is given by:

$$
E p\left(h_{m, n}\right)=\frac{\rho g}{2} \sum_{k=1}^{n} y_{k}^{2}
$$

In the same way, when we use the method of the characteristics, it is necessary to evaluate the terms $\left(h_{m}, \operatorname{div} \varphi_{i}\right)$, which correspond to $\sqrt{\lambda_{i}}\left(h_{m}, p_{i}\right)$. These are the $L^{2}$-projections of water elevation on the basis $\left\{p_{1}, p_{2}, \ldots p_{m}\right\}$ (to within about a multiplicative coefficient). The potential energy can be approximated by:

$$
E p\left(h_{m}\right) \simeq \frac{\rho g}{2} \sum_{k=1}^{m}\left(\frac{\left(h_{m}, p_{k}\right)}{\sqrt{\lambda_{i}}}\right)^{2}
$$


The evolution of potential energy for the approximations of water elevation for 10, 20 and 30 eigen functions is presented in Fig. (1).

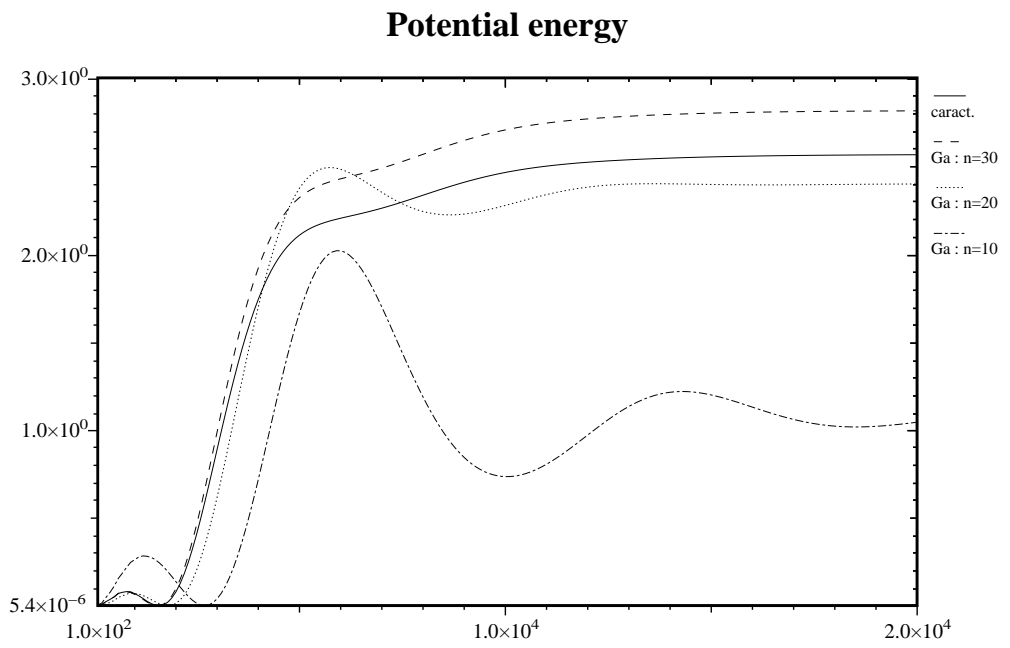

Fig. 1. Comparison between the characteristics and the Galerkin method according to the number of eigen functions.

If we take into account an increasing number of eigen functions, we reduce the oscillations. However, if the number of $p_{i}$ eigen functions (used for elevation) is greater than the number of $\operatorname{grad} p_{k}$ functions (used for velocity, see subsection 2.2 then it appear a high level of numerical instability. It should be noted that the Galerkin method with 30 eigen functions gives a small overestimate of the final potential energy.

In Fig. 2 to 5, we present the simulation results generated using either the Galerkin method with 30 eigen functions or the method of the characteristics to solve the continuity equation. 
Characteristics

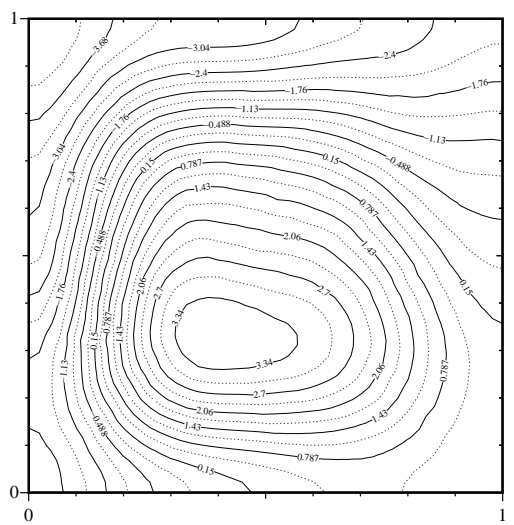

Fig. 2. Variations in water elevation (characteristics).

\section{Characteristics}

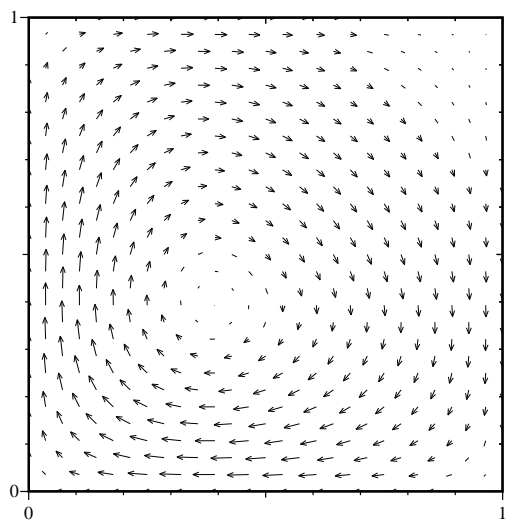

Fig. 4. Velocity field (characteristics).
Galerkin $\mathbf{n}=\mathbf{3 0}$

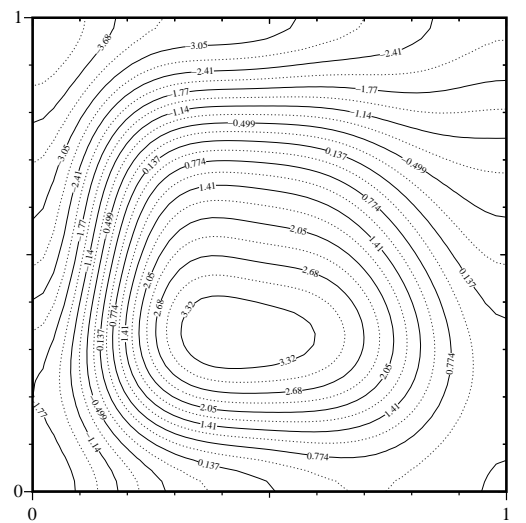

Fig. 3. Variations in water elevation (Galerkin $(\mathrm{n}=30))$.
Galerkin $\mathbf{n}=\mathbf{3 0}$

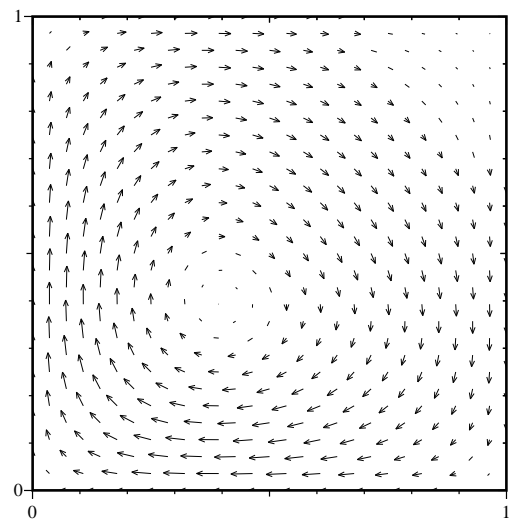

Fig. 5. Velocity field (Galerkin $\mathrm{n}=30$ ). 
We observe a good correspondence between these results. They justify the use of the Galerkin method which is less costly in terms of computation time.

(ii) Comparison between the usual Galerkin method and the nonlinear Galerkin method

Several numerical results have been given $i^{4}$. We simply recall the main steps of the simulation.

The choice of the cut frequency between the large and small components $\left(m_{1}\right.$ and $\left.n_{1}\right)$ is done by using energy criteria. Thus, $m_{1}$ is determined by comparing the ratio of the kinetic energy associated with $y_{m_{1}}$ and $z_{m_{1}}$, and a reference value. We recall that the kinetic energy of $u_{m}$ is given by :

$$
E c\left(u_{m}\right)=\frac{1}{2}\left\|u_{m}\right\|_{L^{2}(\Omega)}^{2}=\frac{1}{2} \sum_{i=1}^{m} X_{i}^{2}
$$

We define two constants, $\epsilon_{u}$ and $\epsilon_{h}$. Thus, the values of $m_{1}$ and $n_{1}$ are determined from the relations :

$$
\begin{aligned}
& m_{1}=\min \left\{M / \forall m_{1}>M, \frac{E c\left(z_{m, n}\right)}{E c\left(y_{m, n}\right)} \leq \epsilon_{u}\right\} . \\
& n_{1}=\min \left\{N / \forall n_{1}>N, \frac{E p\left(\eta_{m, n}\right)}{E p\left(\zeta_{m, n}\right)} \leq \epsilon_{h}\right\} .
\end{aligned}
$$

Note that with these definitions, the values of $m_{1}$ and $n_{1}$ may change over time in order to adapt to the circulation dynamics.

According Jauberteau ${ }^{5}$, we have also implemented a temporal multilevel adaptative method using a V-cycle numerical scheme.

\section{Conclusion}

This work allows us to validate the solution approximation for shallow water equations, using the Galerkin method for both of the model equations. Moreover, it reveals the theoretical justification of the nonlinear Galerkin method for both equations and completes the numerical results presented $\mathrm{in}^{4}$.

\section{References}

1. P. Bisgambiglia and P. Orenga, Résolution numérique d'un problème d'océanographie physique par la méthode de Galerkin, CRAS Vol. 313, I (1991) 627-630.

2. F.J. Chatelon, Analyse d'un problème de shallow water, Thèse de doctorat, Université de Corse, (1996). 
3. F.J. Chatelon and P. Orenga, On a non homogeneous shallow water problem, Math. Mod. and Num. An. Vol. 31, 1 (1997), 27-55.

4. B. Di Martino and P. Orenga, Résolution des équations de shallow water par la méthode de Galerkin non linéaire, RAIRO. sous presse, (1997).

5. F. Jauberteau, Résolution numérique des équations de Navier-Stokes instationnaires par méthodes spectrales - Méthode de Galerkin non linéaire, Thèse de troisème cycle, Université de Paris-Sud (1990).

6. P.K. Kundu, Fluid Mechanics, (Academic press inc, 1990).

7. M. Marion and R. Temam, Nonlinear Galerkin method, SIAM J.Numer. Anal. Vol. 26, 5 (1989), 1139-1157.

8. P. Orenga, Construction d'une base spéciale pour la résolution de quelques problèmes d'Océanographie physique en dimension deux, CRAS Vol. 314, I (1992), 587-590.

9. P. Orenga, Un théorème d'existence de solutions d'un problème de shallow water, Arch. Rational Mech. Anal. Vol. 130, (Springer-Verlag 1995), 183-204. 